\title{
A quem servem as conferências de políticas públicas? Desenho institucional e atores beneficiados ${ }^{1}$
}

Viviane Petinelli

\section{Introdução}

As últimas duas décadas e meia assistiram a emergência, disseminação e institucionalização de uma estrutura participativa no âmbito de diversas políticas públicas e de Casas Legislativas nas três esferas da federação. No nível nacional, esse avanço foi capitaneado, notadamente, pela criação de conselhos nacionais e pela realização de conferências de políticas públicas. Estas últimas se tornaram um símbolo da democracia participativa no país em função da frequência com que foram realizadas, do expressivo contingente de atores individuais e coletivos que envolveram e da diversidade de temas que introduziram e que foram debatidos de forma conjunta pelos segmentos estatal e societal.

Em resposta a esse movimento de democratização da gestão pública brasileira, surgiram diversas investigações preocupadas em aferir e explicar o desempenho ou efetividade dos diversos arranjos participativos, criados e promovidos em contextos políticos distintos. Inicialmente, as análises buscaram compreender e explicar o contexto mais apropriado para a emergência e o sucesso dessas instituições no sentido de promover inclusão política, fortalecer a sociedade civil, reduzir práticas clientelistas, entre outras ações (Abers, 2000, 2001; Avritzer, 2008, 2009; Avritzer e Navarro, 2003; Baiocchi, 2001, 2005; Boschi, 1999; Faria, 2003; Fung, 2004; Schevisbiski, 2007; Tatagiba e Teixeira, 2008; Vitale, 2004).

Mais recentemente, porém, um novo conjunto de investigações emergiu, preocupado com o impacto do desenho das instituições participativas sobre a qualidade da deliberação no interior destas e do conteúdo das propostas aí aprovadas sobre as proposições legislativas e os programas de políticas públicas implementados pelo governo posteriormente (Coelho, 2004, 2007; Cunha, 2013; Petinelli, 2011, 2013, 2014, 2015; Pogrebinschi e Santos, 2011).

Essas investigações têm sugerido uma longa lista de condicionantes contextuais e componentes institucionais relativos ao desenho dos arranjos participativos para explicar o sucesso ou o fracasso dessas experiências criadas em escalas distintas. Nesses estudos, as condições contextuais compreendem desde aspectos políticos e administrativos,

\footnotetext{
1 Este artigo apresenta resultados de uma pesquisa desenvolvida com o apoio do Conselho Nacional de Desenvolvimento Científico e Tecnológico (CNPq), ao qual destino especial agradecimento. Também agradeço as ricas contribuições e sugestões dos parecistas, incorporadas na revisão final deste artigo.
} 
passando por fatores econômicos e geográficos, até aspectos da configuração da sociedade civil do local ou área de política de implementação do arranjo. Já os componentes institucionais englobam o conjunto de regras que definem, entre outros, os objetivos do arranjo, quem e em que proporção participa, como e em que espaços participa, e os resultados esperados de tal participação.

Embora apresentando resultados e interpretações distintas, essa gama de estudos tem mostrado, de forma consensual, que a efetividade das experiências participativas, seja ela no sentido de democratizar o Estado, seja no sentido de democratizar o processo de políticas públicas, é afetada tanto por fatores contextuais relativos à dimensão do Estado e da sociedade civil quanto pelo desenho institucional do arranjo participativo. Ademais, parcela significativa das análises concorda, em maior ou menor grau, com as implicações de certos aspectos dessas três dimensões sobre o desempenho dos arranjos participativos.

Este artigo alinha-se ao campo de estudos sobre a efetividade deliberativa das instituições participativas, particularmente, das conferências de políticas públicas e busca contribuir para essa área de pesquisa. Mas, diferentemente das análises já realizadas, o artigo busca avançar ao lançar luz, de forma inédita, sobre o conteúdo das propostas aprovadas nesses espaços e avaliar se e em que medida as diferentes categorias de atores estatais e não estatais presentes nos encontros conseguem influenciar o resultado final do processo conferencista, expressado no caderno final de resoluções aprovado na conferência nacional.

Tal como diversas investigações que consideram o desenho institucional das conferências um fator condicionante da sua efetividade, acredita-se que as regras quanto à representação e à deliberação nesses espaços impactam diretamente a capacidade de cada categoria influenciar o resultado final do processo. Sabe-se que as regras institucionais definem a representação de participantes por segmento - atores estatais e não estatais - e por categoria dentro de cada segmento, bem como a dinâmica do debate (assuntos tratados) e dos processos decisórios (quantidade de propostas aprovadas e regras para aprovação) - dinâmica deliberativa. Elas determinam a pluralidade da representação, bem como o grau de regulamentação da discussão e da tomada de decisão, produzindo espaços mais ou menos plurais, mais ou menos democráticos e, portanto, mais ou menos inclusivos.

A partir disso se espera que conferências mais inclusivas aprovem propostas de interesse das distintas categorias nelas presentes. Uma dinâmica representativa plural, acompanhada por uma dinâmica deliberativa democrática, possibilita, pelo menos em regra, que os diferentes atores estatais e não estatais participantes da conferência apresentem chances institucionais de influenciar as propostas finais. Por outro lado, na ausência de regras claras quanto à representação e à deliberação, fatores estruturais como a dinâmica de interação dos atores na área de política e as diferentes capacidades de mobilização das diversas categorias podem levar à exclusão de certas vozes e discursos 
ao longo do processo conferencista e, assim, à aprovação de propostas de interesse apenas dos atores politicamente mais influentes.

Para verificar tal proposição, este artigo examina as propostas aprovadas em seis conferências nacionais com desenhos distintos, quais sejam: a $1^{\text {a }}$ Conferência de Aquicultura e Pesca (doravante $1^{a}$ CAP), a $1^{\text {a }}$ Conferência de Cidades (1 ${ }^{\text {a }}$ ConCidades), a $1^{a}$ Conferência de Meio Ambiente (1 $\left.{ }^{a} \mathrm{CMA}\right)$, a $1^{\text {a }}$ Conferência de Esporte (doravante $1^{a}$ $\mathrm{CE})$, a $1^{\text {a }}$ Conferência de Políticas para Mulheres (1 $\left.1^{\mathrm{a}} \mathrm{CPM}\right)$ e a $1^{\text {a }}$ Conferência de Políticas de Promoção da Igualdade Racial (1 ${ }^{a}$ CPIR). Estas foram realizadas no primeiro mandato de Lula (2003-2006) de forma inédita e foram organizadas por ministérios liderados por políticos da base aliada e de partidos de esquerda, em parceria com atores societais. Dessa forma, buscou-se controlar, com vistas a tornar residuais, os efeitos tanto de condicionantes contextuais, tais como vontade política, quanto do aprendizado político sobre os resultados da análise e, assim, destacar o potencial impacto do desenho institucional sobre a capacidade de influência dos atores nas propostas aprovadas em tais conferências.

A capacidade de influência dos atores estatais e não estatais nas propostas aprovadas em cada conferência analisada foi mensurada pela classificação do conteúdo das propostas por categoria(s) à(s) qual(is) a proposta interessava diretamente. Nesse sentido, para cada proposta, identificou-se seu objetivo e buscou-se associá-lo ao discurso e às demandas de alguma(s) categoria(s) no momento de realização da conferência. Com base nessa classificação, mensurou-se o percentual de propostas de interesse direto de cada categoria por conferência e, em seguida, analisou-se a relação entre desenho institucional e capacidade de influência dos diferentes atores nas propostas aprovadas por processo. Ao final, compararam-se as regras quanto à dinâmica representativa e deliberativa dos processos examinados com os resultados obtidos em relação à capacidade de influência das distintas categorias de atores nesses processos.

Este artigo está dividido em três seções, para além desta "Introdução" e das "Considerações finais". Na próxima seção, "Desenho institucional e inclusão política: constatações e hipóteses", mapeiam-se as contribuições mais recentes da literatura sobre a relação entre desenho institucional e inclusão política em arranjos participativos, como as conferências de políticas públicas. Em seguida, em "Desenho institucional da $1^{\text {a }}$ CAP, $1^{\text {a }}$ ConCidades, $1^{\text {a }} \mathrm{CMA}, 1^{\text {a }} \mathrm{CE}, 1^{\text {a }} \mathrm{CPM}$ e $1^{\text {a }} \mathrm{CPIR}$ e seus possíveis efeitos sobre a inclusão política", descreve-se o desenho institucional dessas conferências a fim de sugerir os efeitos esperados deste sobre a capacidade de inclusão política e os respectivos impactos no resultado final de tais conferências. Na seção, "A quem serviram a $1^{\text {a }} \mathrm{CAP}, 1^{a}$ ConCidades, $1^{\text {a }} \mathrm{CMA}, 1^{\text {a }} \mathrm{CE}, 1^{\text {a }} \mathrm{CPM}$ e $1^{\text {a }} \mathrm{CPIR}$ : a relação entre desenho institucional e propostas aprovadas, apresentam-se a metodologia e os resultados obtidos acerca da capacidade de influência das diferentes categorias de atores no caderno final de cada conferência e se examina a relação entre desenho institucional e atores beneficiados pelas propostas nela aprovadas. 


\section{Desenho institucional e inclusão política: constatações e hipóteses}

Os efeitos das regras e dos procedimentos institucionais sobre o comportamento e as decisões públicas dos atores políticos e societais têm sido objeto de preocupação de cientistas políticos há mais de um século. Não constitui nenhuma novidade avaliar e explicar o funcionamento do sistema político como um todo e de suas instituições políticas, tais como os parlamentos, os partidos e o Poder Judiciário, a partir de legislações das mais variadas espécies. A originalidade repousa, na verdade, na aplicação dessa abordagem às inovações democráticas, às instituições e aos canais participativos, cuja origem não se encontra no processo de autorização da representação nem exclusivamente em atos normativos, como as instituições políticas (Avritzer, 2008).

A interpretação pioneira acerca da relação entre desenho institucional e seus resultados em termos de inclusão política foi realizada pela vertente da democracia deliberativa empoderada (DDE), considerada um braço da teoria deliberativa (Baiocchi, 2001). A DDE postula que o desenho institucional constitui a principal ferramenta para aproximar as instituições do ideal deliberativo e, por conseguinte, aprofundar a democracia via inclusão política. As regras e os procedimentos que pautam as atitudes e as escolhas dos indivíduos podem ser delineados de tal forma a garantir ampla participação e pluralidade de representação, bem como legitimidade, justiça e eficiência das decisões tomadas. Uma vez que o desenho define quem participa e em que proporção, como e onde participa e quais os resultados esperados de tal participação, ele pode tanto promover quanto dificultar a apresentação de razões e o debate de alternativas pelos partícipes do processo, levando-se em consideração o argumento apresentado pelos outros ao longo da interação discursiva (Fung e Wright, 2003).

Sob a ótica da DDE, um arranjo institucional é tanto mais inclusivo quanto mais deliberativo ele é. Por sua vez, um desenho é tanto mais deliberativo quanto mais público e plural ele é; quanto mais reguladas e livres de coerção externa e de manipulação por grupos com maior poder político e econômico são as discussões nele desenroladas; e quanto mais racionalmente motivadas, reinterpretadas e representativas são as decisões nele tomadas. Quando, porém, o desenho é fechado, elitista e/ou excludente e, nele, o debate é pouco ou nada regulado e/ou é manipulado e as decisões tomadas não passam por um processo de troca argumentativa razoável, a inclusão política é prejudicada e o processo gera decisões menos legítimas e justas.

A sobrerrepresentação e/ou a exclusão de determinadas vozes pelas regras relativas à participação, à representação ou ao processo deliberativo implicam, respectivamente, a sobrerrepresentação e/ou a exclusão de certas narrativas dos espaços participativos. Uma vez que os discursos impactam os interesses e as ideias dos indivíduos (Hajer e Wagenaar, 1995; Fisher, 1993), o privilegiamento e/ou a consideração de apenas alguns dos sistemas discursivos em disputa geram escolhas relativamente menos representativas e, portanto, menos legítimas e justas. 
A possibilidade de produzir efeitos negativos em termos de inclusão política pelo desenho institucional delineado exige, portanto, uma atenção especial na definição e na coordenação da participação, da representação e da deliberação nas experiências democráticas. Embora participação e deliberação sejam atividades que têm como objetivo democratizar as decisões públicas pela discussão, elas constituem ações contraditórias, embora não excludentes (Faria, Silva e Lins, 2012). A participação pressupõe um envolvimento direto, amplo e sustentado dos cidadãos nas questões públicas. Como tal, ela se preocupa mais com a publicidade e a inclusão enquanto condição para a efetividade e a legitimidade da política do que com a qualidade das razões apresentadas para justificar as preferências dos atores nelas envolvidos (Papadopoulos e Warin, 2007).

Por sua vez, a deliberação opera mais eficientemente em pequenas escalas e às custas do insulamento do público geral (Cohen e Fung, 2004). Como decorrência, a qualidade da discussão ganha centralidade no que se refere, notadamente, à dimensão argumentativa do debate, e a publicidade e a ampla participação perdem espaço para a representação. A inclusão se limita a uma amostra representativa da população, dada a necessidade de restringir o debate a um pequeno grupo de atores para que os seus resultados sejam legítimos e justos (Ramos, 2013).

Para dar conta dessa tensão, autores como Fung (2004), Hendriks (2006), Mansbridge (1999, 2007, 2010) e Goodin (2005) apostam em arranjos que envolvam tanto a dimensão participativa como a deliberativa. Por um lado, esses autores estão preocupados em compatibilizar essas formas de ação de modo a superar as contradições a elas inerentes. Por outro, eles buscam localizar a deliberação em um processo decisório mais amplo que pode envolver tanto publicidade e ampla participação direta dos cidadãos, próprios à participação, quanto seleção e restrição da participação, próprios à deliberação.

Esses tipos de desenho, que combinam, em menor ou maior medida, ampla participação com representação em múltiplos espaços deliberativos, produzindo ora mais ora menos inclusão política, têm caracterizado diferentes arranjos participativos brasileiros, a saber, o orçamento participativo (OP), o plano diretor municipal (doravante PDM), os conselhos gestores e as conferências de políticas públicas.

O OP apresenta um desenho de baixo para cima (bottom-up), que se caracteriza pela livre entrada e pela participação de qualquer cidadão no processo de discussão e tomada de decisão acerca do orçamento público local e da forma de alocação deste. Nele, os cidadãos apresentam autonomia para definir as regras dos processos decisórios e autoridade para decidir sobre a distribuição e a destinação de recursos orçamentários (Avritzer, 2008, 2009). Como tal, este desenho pode apresentar elevado potencial inclusivo ao envolver diversas etapas descentralizadas, ser aberto à participação de qualquer cidadão, sem a necessidade de representação, e possibilitar regras favoráveis à deliberação (Fung, 2004).

Por sua vez, o PDM consiste em uma ferramenta legal de ratificação pública, pela qual os atores da sociedade civil são chamados a referendar a proposta de ordenamento 
do território municipal apresentada pelo governo e pelos legisladores em audiências e assembleias públicas. A participação social nesse caso é apenas ratificadora, não substituindo o processo de deliberação e de tomada de decisão pelos atores políticos posteriormente. O potencial inclusivo desse desenho está associado, portanto, a sua capacidade de mobilização e inclusão de vozes no processo decisório. Caso esta não exista, as decisões tomadas não incluirão, a priori, as opiniões e a vontade dos atores societais em relação à política urbana (Avritzer, 2008, 2009; Boschi, 1999).

Já no caso dos conselhos gestores, a capacidade de inclusão política decorre da combinação de representação com deliberação. Os conselhos são instâncias permanentes de participação de representantes estatais e não estatais, nas quais os atores discutem e tomam decisões conjuntamente sobre propostas para determinada área de política pública. Seu desenho de partilha de poder pode assegurar processos decisórios argumentativos, regulados, livres de coerção interna e externa e abrangentes tematicamente (Avritzer, 2008, 2009; Avritzer e Navarro, 2003; Vitale, 2004).

Por outro lado, ao se basearem na representação, esses arranjos restringem a participação dos cidadãos a um número pequeno de representantes. A baixa publicidade pode ser acompanhada, ademais, por regras que não necessariamente garantam pluralidade e inclusão dos diversos grupos envolvidos com a política. Ao privilegiar um ou outro segmento - Estado ou sociedade civil - e uma ou mais categorias dentro de cada segmento - ONGs, movimentos sociais, atores de mercado, entre outros -, sem a finalidade de promover igualdade política, o desenho de partilha de poder pode não garantir pluralidade e inclusão política, o que impacta negativamente a efetividade deliberativa desses arranjos (Coelho, 2004, 2007; Faria e Ribeiro, 2010; Schevisbiski, 2007).

Dentre as instituições participativas brasileiras, as conferências apresentam o desenho que pode melhor superar as contradições entre participação, representação e deliberação e melhor compatibilizar essas três formas de ação. Grosso modo, as conferências constituem espaços integrados de participação, deliberação e representação, que agregam representantes estatais e societais em diferentes esferas da federação, com o objetivo de discutir e tomar decisões em relação a diferentes políticas públicas (Petinelli, 2014).

Embora conceitualmente parecidos, o desenho das conferências tem assumido contornos próprios de acordo com a área em que são realizadas. Elas podem ter como objetivo, entre outros, propor políticas, promover maior participação política de grupos minoritários e historicamente excluídos, difundir ideias e firmar compromissos e/ou avaliar os programas e ações governamentais implementados até o momento do encontro (Souza, 2013).

Esses objetivos podem ser discutidos em processos mais ou menos descentralizados. Algumas conferências compreendem encontros locais, distritais, virtuais e/ou municipais, enquanto outras são mais centralizadas, envolvendo somente etapas estaduais e regionais, para além do encontro nacional, comum a todos os processos. A 
maioria significativa das conferências tem abrangido, pelo menos, encontros municipais, estaduais e nacionais. Encontros locais, distritais e virtuais anteriores à etapa municipal são mais difíceis de ser observados (Avritzer e Souza, 2013).

Como decorrência desse escalonamento, as conferências podem envolver um conjunto ora mais ora menos amplo e diversificado de atores estatais e não estatais, que vão desde representantes governamentais e legisladores, passando por atores vinculados a organizações da sociedade civil e do mercado, até cidadãos individuais interessados em determinada política. Esses atores podem participar, com direito de voz - delegados, convidados e ouvintes - e/ou de voto - somente delegados -, em espaços diversos de discussão e de tomada de decisão.

Nesses encontros, os representantes estatais e não estatais participam em proporções variadas, que podem ser mais ou menos equilibradas. Além disso, as regras definidas para cada processo de conferências podem privilegiar um segmento específico e, dentro de cada segmento, uma categoria específica ou distribuir igualmente o número de delegados entre eles. Algumas conferências asseguram ainda cotas de representação para determinados grupos sociais, considerados historicamente excluídos dos processos de tomada de decisão pública no país, tais como as mulheres e os grupos étnico-raciais (Petinelli, 2014).

Geralmente os delegados, selecionados ou indicados, participam dos processos conferencistas por meio de grupos de trabalho (GTs) e plenárias. Os GTs constituem espaços de discussão e de tomada de decisão, nos quais os participantes debatem um ou todos os temas tratados na conferência. Nesses espaços, o processo discursivo e decisório pode ser livre ou orientado por um documento-base, composto por propostas de políticas formuladas pelas instituições organizadoras do encontro. Quando livre, os delegados podem apresentar propostas sobre determinado assunto livremente, a partir de suas próprias ideias, experiências e interesses. Quando, porém, for orientado por um texto-base de discussão, o debate torna-se mais restrito e direcionado. Nesse caso, os delegados devem discutir e decidir sobre as propostas contidas no documento-base e, se permitido, apresentar novas propostas sobre o tema em debate. Nesses espaços, tanto as sugestões governamentais como as propostas inéditas dos delegados participantes, quando permitidas, devem ser apreciadas, podendo ser aprovadas integral ou parcialmente ou ser rejeitadas por certo número de delegados, definido ou não no regulamento interno da conferência (Petinelli, 2014).

As propostas aprovadas nos GTs são, geralmente, reunidas em um único documento para ser votadas na plenária final. Esta consiste no último momento da conferência em suas diferentes etapas e é um espaço, sobretudo, de tomada de decisão, quando as propostas não podem ser modificadas; elas devem ser aprovadas na íntegra ou com as alterações propostas nos GTs, ou ser rejeitadas completamente. Novas propostas também não são aceitas nesses espaços; embora, em certos encontros, as propostas 
possam ser defendidas, em geral, por um ou mais delegados a favor e um ou mais contra antes de passar pelo escrutínio da plenária.

De modo geral, portanto, a despeito das particularidades observadas por área de política, o desenho institucional das conferências tem assegurado ampla participação dos cidadãos (Almeida, 2013; Avritzer, 2013; Cunha, 2013; Faria e Lins, 2013; Pogrebinschi, 2013; Ramos, 2013) e apresentado fortes elementos deliberativos (Ramos e Faria, 2013). Seu grau de inclusão decorre, de um lado, da pluralidade de atores societais e governamentais envolvidos no processo e, de outro, do potencial deliberativo dos espaços de discussão e de tomada de decisão presentes ao longo desse processo.

Este artigo parte dessas constatações acerca do potencial inclusivo das conferências, dado pelo desenho institucional que assumem, para avaliar se e em que medida as propostas aprovadas na $1^{\text {a } C A P,} 1^{\text {a }}$ ConCidades, $1^{\text {a } C M A}, 1^{\text {a }} \mathrm{CE}, 1^{\text {a }} \mathrm{CPM}$ e $1^{\mathrm{a}}$ CPIR, as quais interessavam diretamente a alguma(s) categoria(s) presente(s) nesses processos, refletiram a capacidade inclusiva desses espaços, decorrente do desenho institucional assumido por cada um deles.

Nesse sentido, o artigo investiga o potencial de inclusão política da $1^{a}$ CAP, $1^{a}$ ConCidades, $1^{\text {a }} \mathrm{CMA}, 1^{\mathrm{a}} \mathrm{CE}, 1^{\mathrm{a}} \mathrm{CPM}$ e $1^{\mathrm{a}} \mathrm{CPIR}$ a partir da dinâmica representativa e deliberativa dessas conferências. A dinâmica representativa é observada pelo método de seleção - eleição e indicação - e pela composição dos delegados das conferências por segmento - atores estatais e societais - e por categoria dentro de cada segmento - atores governamentais municipais, estaduais e federais, movimentos sociais, organizações da sociedade civil, atores de mercado etc. Por sua vez, a dinâmica deliberativa é examinada a partir do conjunto de normas que regulamentam o debate e a tomada de decisão nos diferentes espaços participativos ao longo do processo conferencista².

Tal como postulado pela literatura apresentada, acredita-se que o grau de inclusão política é tanto maior quanto mais plural é a participação direta e/ou por meio de representantes nesses espaços. Entende-se que conferências que asseguram representação da pluralidade de atores societais envolvidos com a política tendem a ser mais inclusivas, se comparadas aos encontros nos quais a participação se dá exclusivamente por meio de indicação e não há regras quanto à composição da representação. Nesses últimos, os grupos politicamente mais influentes podem ser sobrerrepresentados, o que afetaria diretamente a pluralidade e, por conseguinte, a capacidade de inclusão da conferência. Nas conferências que asseguram a representação de todas as categorias estatais e não estatais nelas envolvidas, por sua vez, a pluralidade e a inclusão estariam, pelo menos em regra, asseguradas.

\footnotetext{
2 Em que pese o fato de a dinâmica deliberativa ser afetada por fatores intervenientes como o perfil, o nível de conhecimento e o nível de experiência dos atores, esta foi avaliada exclusivamente pela presença ou não de regras que regulamentam o debate e o processo decisório nos processos conferencistas. Acredita-se que o próprio arcabouço institucional que define tal dinâmica pode tanto aprofundar como reduzir disparidades existentes e, por conseguinte, contribuir para a maior ou menor capacidade de influência dos diferentes atores ao longo do processo conferencista.
} 
Ademais, supõe-se que conferências que garantem debate e processo decisório regulamentados, pelo qual todos os discursos presentes podem influenciar os resultados do processo deliberativo por meio da modificação de propostas apresentadas e sugestão de novas propostas, são mais inclusivas. Um processo deliberativo regulamentado pode possibilitar que grupos menos representados tenham voz e demandas aprovadas, sem ter que recorrer a alianças políticas. Da mesma forma, um processo deliberativo regulamentado pode dificultar e, até mesmo, impedir que atores menos representados aprovem recomendações de seu interesse ao exigir, por exemplo, maiorias simples e/ou qualificadas para aprovação de diretrizes em grupos de trabalho (GTs) e nas plenárias ao longo do processo conferencista.

Da combinação de dinâmica representativa e dinâmica deliberativa, resulta, por hipótese, a capacidade de influência dos atores nas propostas aprovadas nas conferências. Acredita-se que os processos conferencistas que asseguram formalmente participação plural e equilibrada de atores societais em espaços deliberativos que exigem minorias, em vez de maiorias, para apresentação e aprovação de propostas geram resultados mais representativos dos diferentes segmentos nelas representados, isto é, um conjunto diversificado de propostas de interesse de todas as categorias representadas no processo, em proporções, por hipótese, próximas à composição da representação assegurada.

Por outro lado, de conferências com menor grau de inclusão política, acredita-se resultar um conjunto de propostas menos representativo e legítimo dos diversos interesses e discursos presentes. Propostas de interesse direto e individual de categorias menos influentes politicamente tendem a não ser aprovadas e a capacidade de influência destas tende a resultar de sua capacidade de articulação e inclusão de suas demandas, em alguma medida, nas propostas de interesse de outras categorias.

Na próxima seção, o desenho da $1^{\text {a } C A P}, 1^{\text {a }}$ ConCidades, $1^{a} \mathrm{CMA}, 1^{\mathrm{a}} \mathrm{CE}, 1^{\mathrm{a}} \mathrm{CPM}$ e $1^{\text {a }}$ CPIR é descrito e, ao final, são apresentados os efeitos esperados desse desenho sobre a capacidade de inclusão política e os efeitos dessa capacidade sobre o conteúdo das propostas aprovadas em tais conferências.

\section{Desenho institucional da $1^{\text {a }}$ CAP, $1^{\text {a }}$ ConCidades, $1^{\text {a }}$ CMA, $1^{\text {a }}$ CE, $1^{\text {a }}$ CPM e $1^{a}$ CPIR e seus possíveis efeitos sobre a inclusão política}

Há oito décadas (1937), foi instituído, por ato normativo do então presidente Getúlio Vargas, o primeiro arranjo participativo do Brasil. Embora criadas sem tais pretensões, as conferências tornaram-se importantes espaços de inclusão de vozes societais na política de saúde na década de 1970 e, a partir da redemocratização do país em 1985, num amplo e diversificado conjunto de políticas setoriais, tais como a política urbana, de aquicultura e pesca, de meio ambiente, de esporte, e as políticas para mulheres e de promoção de igualdade racial. 
De 1941 a 2014, foram realizados 144 processos conferencistas em mais de 40 áreas de políticas, com a participação de aproximadamente 9 milhões de pessoas. Dessas conferências, 34 aconteceram até 2002 e debateram cinco temas distintos, a saber, Saúde, Assistência Social, Direitos Humanos, Direitos da Criança e do Adolescente e Segurança Alimentar e Nutricional. Outras 31 foram organizadas recentemente pelo primeiro governo Dilma entre 2011 e 2014 e as demais 72 aconteceram nos governos Lula (2003-2010) e discutiram, de forma inédita, 35 políticas distintas. Em suas diversas etapas presenciais e/ou virtuais, esses processos envolveram mais de 7 milhões de pessoas em todo o país (Brasil, 2016).

A proliferação e a diversificação temática das conferências geraram grande variação no desenho institucional desses espaços. Tanto os objetivos quanto a dinâmica representativa e deliberativa desses processos ganharam contornos próprios e particulares de acordo com a política tratada neles. Desses contornos institucionais variados, têm resultado conferências ora mais, ora menos inclusivas em decorrência das normas que regulamentam a participação, a representação e a deliberação presentes nelas.

O Quadro 1 apresenta a dinâmica representativa da $1^{\text {a }}$ CAP, $1^{\text {a }}$ ConCidades, $1^{a}$ CMA, $1^{\text {a }} \mathrm{CE}, 1^{\text {a }} \mathrm{CPM}$ e $1^{\text {a }} \mathrm{CPIR}$, tal como definida no regimento interno (RI) e demais documentos que regulamentaram essas conferências (Brasil, 2003c, 2003e, 2003f, 2004a, 2004c, 2005). De modo geral, o que se constata é uma variação entre os processos, embora com algumas regras semelhantes entre eles. 


\section{Quadro 1 \\ Dinâmica representativa da $1^{\mathrm{a}} \mathrm{CAP}, 1^{\mathrm{a}}$ ConCidades, $1^{\text {a }}$ CMA, $1^{\text {a }}$ CE, $1^{\text {a }}$ CPM e $1^{\text {a }}$ CPIR}

\begin{tabular}{|c|c|}
\hline Conferência & Dinâmica representativa \\
\hline $1^{\text {a }}$ CAP & $\begin{array}{l}\text { Eleição de } 3 \text { representantes efetivos e } 3 \text { suplentes por sindicato, movimento e } \\
\text { associação da área nos estados; } \\
\text { Indicação de } 3 \text { representantes efetivos e } 3 \text { suplentes por órgão estadual; } \\
\text { Eleição entre pares de, no mínimo, } 1 \text { representante de cada sindicato, } \\
\text { movimento, associação e órgão estatal para o encontro nacional (critério: eleição } \\
\text { de } 1 \text { para cada } 5 \text { delegados na etapa estadual). }\end{array}$ \\
\hline $\begin{array}{l}1^{\mathrm{a}} \\
\text { ConCidades }\end{array}$ & $\begin{array}{l}\text { Participação livre na etapa inicial, com seleção de delegados para as conferências } \\
\text { estaduais, sendo: } 40 \% \text { do governo e } 60 \% \text { da sociedade civil; } \\
\text { Distribuição da participação da sociedade civil em: } 25 \% \text { para movimentos sociais } \\
\text { e populares, } 7,5 \% \text { para ONGs, entidades profissionais, acadêmicas e de pesquisa, } \\
10 \% \text { para trabalhadores, } 7,5 \% \text { para empresários e } 10 \% \text { de operadores e } \\
\text { concessionários de serviços públicos. }\end{array}$ \\
\hline $1^{\text {a }} \mathrm{CMA}$ & $\begin{array}{l}\text { Participação livre na etapa inicial, com seleção de delegados para as conferências } \\
\text { estaduais, sendo: } 20 \% \text { do governo e } 80 \% \text { da sociedade civil; } \\
\text { Distribuição da participação da sociedade civil em: } 50 \% \text { para ONGs, movimentos } \\
\text { sociais, comunidades tradicionais e povos indígenas e } 30 \% \text { para setor } \\
\text { empresarial. }\end{array}$ \\
\hline $1^{\mathrm{a}} \mathrm{CE}$ & $\begin{array}{l}\text { Participação livre na etapa inicial, com seleção por consenso, votação nominal ou } \\
\text { votação por chapa; } \\
\text { Proporção de representantes por segmento e categoria sem regras estabelecidas } \\
\text { pelo RI dos encontros. }\end{array}$ \\
\hline $1^{\text {a }}$ CPM & $\begin{array}{l}\text { Participação livre na etapa inicial, com seleção de delegados para as conferências } \\
\text { estaduais e nacional, sendo: } 40 \% \text { do governo e } 60 \% \text { da sociedade civil. }\end{array}$ \\
\hline $1^{\text {a }}$ CPIR & $\begin{array}{l}\text { Participação livre na etapa inicial; } \\
\text { Regras de seleção e distribuição da representação não estabelecidas pelo RI dos } \\
\text { encontros. }\end{array}$ \\
\hline
\end{tabular}

Fonte: Formulação própria com base no regimento de cada conferência (Brasil, 2003c, 2003e, 2003f, 2004a, 2004c, 2005).

Observam-se regras claras quanto à composição e à distribuição da representação entre atores estatais e societais na $1^{\text {a }}$ CAP, $1^{\text {a }}$ ConCidades, $1^{\text {a }}$ CMA e $1^{\text {a }}$ CPM. Destas, apenas a $1^{\text {a }}$ CAP assegurou, pelo menos na etapa inicial, paridade de representação entre atores governamentais e não governamentais e entre os diversos atores societais. No entanto, tal como desenhada com paridade de representação, mas sem limite na quantidade de instituições representadas e de representantes participantes por encontro, a dinâmica representativa dessa conferência pode ter favorecido a participação da(s) categoria(s) com maior número de entidades representativas, no caso, a dos pescadores artesanais e aquicultores familiares (Petinelli, 2014). Os outros três processos privilegiaram, formalmente, a representação da sociedade civil e, dentro desse segmento, os atores sociais (movimentos sociais, entidades civis, ONGs) ante os atores de mercado (empresários, prestadores de serviço, operadores, concessionários).

Por sua vez, a $1^{a}$ CE e a $1^{\text {a }}$ CPIR não estabeleceram, no respectivo regimento interno (RI), critérios de seleção e de composição da representação ao longo do processo. Isso pode ter produzido uma dinâmica representativa menos plural, com a exclusão de certas vozes e discursos ao longo do processo conferencista e o favorecimento de 
demandas de segmentos politicamente mais influentes na respectiva área; no caso da política de esporte, a comunidade de esporte profissional; e, no caso das políticas de promoção da igualdade racial, os movimentos negros (Petinelli, 2014).

Da dinâmica representativa dos seis processos conferencistas, resultariam, portanto, conferências pouco representativas, embora plurais, haja vista o privilegiamento à representação de certos atores tanto pelas regras estabelecidas como pela ausência delas. Sob tal configuração, os atores aprovariam um número mais expressivo de recomendações de seu interesse e, ao mesmo tempo, bloqueariam propostas contrárias as suas preferências ao longo do processo.

No entanto, uma dinâmica representativa plural, mas que tende a produzir resultados pouco representativos, pode se tornar mais representativa na presença de regras que possibilitam a apresentação e a aprovação de toda e qualquer demanda, sem a necessidade de maiorias para aprová-la. Ao estabelecer critério de maioria simples ou qualificada, o processo conferencista pode eliminar a chance de influência de grupos menos representados e forçá-los a fazer alianças e trocas políticas para que suas propostas sejam, em alguma medida, consideradas.

Esse pode ter sido o caso da $1^{\text {a }}$ CAP e da $1^{\text {a }}$ CPM, cuja aprovação de propostas nos GTs e na plenária final requeria maioria simples de votos dos delegados presentes, como mostra o Quadro 2. A possibilidade de maior representação do segmento dos pescadores artesanais e aquicultores familiares na $1^{\text {a }}$ CAP e de maior representação de atores sociais em relação aos governamentais na $1^{\text {a }}$ CPM, somadas à exigência de maioria simples para aprovação de recomendações na plenária final, podem ter favorecido, significativamente, a aprovação de propostas desses grupos ao longo do processo.

Por sua vez, a $1^{\text {a }}$ CMA pode ter produzido um resultado final mais representativo, não obstante a dinâmica representativa desse processo favorecer os atores sociais, notadamente, representantes de movimentos ambientalistas. Pelo menos na etapa nacional, a dinâmica deliberativa permitiu a aprovação de propostas por somente $20 \%$ dos delegados presentes. Dessa forma, até as recomendações de atores menos representados poderiam ser aprovadas ao final da $1^{\text {a }}$ CMA.

Já a $1^{\text {a }}$ ConCidades, $1^{a}$ CE e $1^{a}$ CPIR, ao se silenciarem quanto à dinâmica deliberativa, podem ter reforçado os resultados produzidos pela dinâmica representativa, em que pese a especificação de regras para discussão não necessariamente assegurar uma dinâmica deliberativa democrática. A $1^{\text {a }}$ ConCidades privilegiou, formalmente, a representação não estatal e, dentro desse segmento, dos movimentos urbanos frente aos atores de mercado (empresários, operadores e concessionários). A $1^{\text {a }}$ CE e a $1^{\text {a }}$ CPIR, por seu turno, não definiram regras de representação, o que pode ter levado à sobrerrepresentação dos grupos politicamente mais proeminentes em cada área comunidade do esporte profissional e movimentos negros, respectivamente. Na ausência de regras quanto ao debate e à tomada de decisão, os dois processos podem ter produzido resultados pouco representativos pelo favorecimento de alguns em relação a outros. 


\section{Quadro 2 \\ Dinâmica deliberativa da $1^{\text {a }}$ CAP, $1^{\text {a }}$ ConCidades, $1^{\text {a }}$ CMA, $1^{\text {a }}$ CE, $1^{\text {a }}$ CPM e $1^{\text {a }}$ CPIR}

\begin{tabular}{|c|c|}
\hline Conferência & Dinâmica deliberativa \\
\hline $1^{\text {a }}$ CAP & $\begin{array}{l}\text { Debate e tomada de decisão sem regras estabelecidas no RI dos encontros } \\
\text { estaduais; } \\
\text { Novas emendas subscritas por, pelo menos, } 10 \% \text { do total de delegados na etapa } \\
\text { nacional; } \\
\text { Apreciação de propostas, na plenária final, aprovadas por, no mínimo, } 30 \% \text { dos } \\
\text { delegados nas plenárias setoriais; } \\
\text { Aprovação das propostas finais por maioria simples. }\end{array}$ \\
\hline $\begin{array}{l}1 \text { a } \\
\text { ConCidades }\end{array}$ & Debate e tomada de decisão sem regras estabelecidas no RI ao longo do processo. \\
\hline $1^{\text {a }}$ CMA & $\begin{array}{l}\text { Debate livre e aprovação de propostas nos GTs e plenária estadual por maioria } \\
\text { simples; } \\
\text { Aprovação de propostas nos GTs e plenária final da etapa nacional por, pelo menos, } \\
20 \% \text { dos delegados. }\end{array}$ \\
\hline $1^{\mathrm{a}} \mathrm{CE}$ & Debate e tomada de decisão sem regras estabelecidas no RI ao longo do processo. \\
\hline $1^{\text {a }}$ CPM & $\begin{array}{l}\text { Propostas aprovadas por unanimidade dos GTs consideradas aprovadas pela } \\
\text { conferência. } \\
\text { Propostas aprovadas em um ou mais grupos do mesmo eixo temático e as não } \\
\text { aprovadas, mas com, no mínimo, } 20 \% \text { da votação nos grupos, apreciadas em } \\
\text { plenário; } \\
\text { Aprovação de propostas nos GTs e na plenária final por maioria simples. }\end{array}$ \\
\hline $1^{\text {a } \text { CPIR }}$ & Debate e tomada de decisão sem regras estabelecidas no RI ao longo do processo. \\
\hline
\end{tabular}

Fonte: Formulação própria com base no regimento de cada conferência (Brasil, 2003c, 2003e, 2003f, 2004a, 2004c, 2005).

O Quadro 3 apresenta os efeitos esperados do desenho institucional da $1^{\text {a }}$ CAP, $1^{\text {a }}$ ConCidades, $1^{\text {a }}$ CMA, $1^{\text {a }} \mathrm{CE}, 1^{\text {a }} \mathrm{CPM}$ e $1^{\text {a }}$ CPIR sobre a capacidade de influência dos atores nelas representados. Espera-se capacidade de influência desigual entre os atores societais em todos os processos. Acredita-se que o desenho da $1^{\text {a }}$ CAP, $1^{\text {a }}$ ConCidades, $1^{\text {a }}$ CMA e $1^{\text {a }}$ CPM reforçou o favorecimento do RI a certos grupos, o que, por sua vez, gerou um processo plural, mas menos representativo. De modo similar, a ausência de regras quanto à dinâmica representativa e à deliberativa na $1^{\text {a }}$ CE e $1^{\text {a }}$ CPIR acarretou, por hipótese, um processo mais elitizado e com resultados menos representativos, traduzido na maior capacidade de influência dos grupos politicamente mais influentes de cada área. 


\section{Quadro 3 \\ Efeitos esperados do desenho institucional da $1^{\text {a }}$ CAP, $1^{\text {a }}$ ConCidades, $1^{\text {a }}$ CMA, $1^{\text {a }}$ CE, $1^{\text {a }}$ CPM e $1^{\text {a }}$ CPIR sobre a capacidade de influência dos atores nelas presentes}

\begin{tabular}{|c|c|c|}
\hline Conferência & Desenho institucional & Capacidade de influência dos atores \\
\hline $1^{\text {a } ~ C A P ~}$ & $\begin{array}{l}\text { Plural, mas pouco } \\
\text { representativo. }\end{array}$ & $\begin{array}{l}\text { Desigual, com maior capacidade de influência de } \\
\text { pescadores artesanais e aquicultores familiares. }\end{array}$ \\
\hline $\begin{array}{l}1^{\text {a }} \\
\text { ConCidades }\end{array}$ & $\begin{array}{l}\text { Plural, mas pouco } \\
\text { representativo. }\end{array}$ & $\begin{array}{l}\text { Desigual, com maior influência de movimentos } \\
\text { urbanos. }\end{array}$ \\
\hline $1^{\text {a }}$ CMA & $\begin{array}{l}\text { Plural, mas pouco } \\
\text { representativo. }\end{array}$ & $\begin{array}{l}\text { Desigual, com maior capacidade de influência de } \\
\text { movimentos ambientalistas. }\end{array}$ \\
\hline $1^{a} \mathrm{CE}$ & $\begin{array}{l}\text { Sujeito a elitização e baixa } \\
\text { representatividade. }\end{array}$ & $\begin{array}{c}\text { Desigual, com maior influência da comunidade do } \\
\text { esporte profissional. }\end{array}$ \\
\hline $1^{\text {a }} \mathrm{CPM}$ & $\begin{array}{l}\text { Plural, mas pouco } \\
\text { representativo. }\end{array}$ & $\begin{array}{c}\text { Desigual, com maior influência dos movimentos } \\
\text { feministas. }\end{array}$ \\
\hline $1^{\text {a }}$ CPIR & $\begin{array}{l}\text { Sujeito a elitização e baixa } \\
\text { representatividade. }\end{array}$ & $\begin{array}{l}\text { Desigual, com maior capacidade de influência dos } \\
\text { movimentos negros. }\end{array}$ \\
\hline
\end{tabular}

Fonte: Formulação própria.

A seguir, avalia-se se e como o desenho institucional desses encontros impactou as propostas neles aprovadas, as quais interessavam diretamente a alguma(s) categoria(s) presente(s) neles.

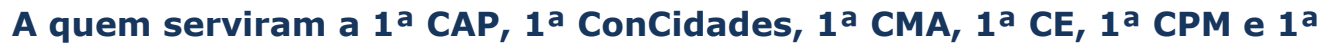 CPIR: a relação entre desenho institucional e propostas aprovadas}

O desenho institucional das conferências pode produzir maior ou menor inclusão política, de acordo com as regras definidas em relação à dinâmica representativa e deliberativa delas. Conferências nas quais há pluralidade de representação e um processo discursivo e decisório democrático são mais inclusivas, comparativamente a encontros em que as regras não favorecem a representação e a deliberação de todas as categorias envolvidas com a respectiva política.

De conferências politicamente inclusivas, espera-se que resulte um conjunto de propostas mais representativo dos diversos interesses em disputa, uma vez que as regras asseguram voz, voto e poder de influência a todos, em alguma medida. E, na ausência de regras claras quanto à representação e à deliberação, as disparidades de recursos e capacidades dos atores podem levar à exclusão de certas vozes e discursos ao longo do processo conferencista e, assim, à aprovação de propostas de interesse apenas das categorias politicamente mais influentes presentes nos encontros.

Tendo isso em vista, este artigo examina o conteúdo das propostas aprovadas na $1^{\text {a } C A P}, 1^{\text {a }}$ ConCidades, $1^{\text {a }} \mathrm{CMA}, 1^{\text {a }} \mathrm{CE}, 1^{\text {a }} \mathrm{CPM}$ e $1^{\text {a }} \mathrm{CPIR}$, a fim de verificar a relação entre desenho institucional e atores beneficiados pelas propostas nelas aprovadas. As propostas aprovadas foram individualmente classificadas por categoria diretamente interessada nelas e, ao final, agregadas por conferência, a fim de possibilitar a comparação entre o grau de inclusão política do encontro e o resultado final de cada um deles em 
termos de propostas aprovadas por categoria representada. Nas subseções abaixo, apresentam-se a metodologia utilizada e as constatações empíricas dessa análise.

Metodologia de pesquisa

Dois tipos de metodologia têm sido utilizados para avaliar a capacidade das instituições participativas em cumprir seus objetivos. De um lado, encontram-se as análises que investigam as práticas participativas pela ótica dos atores por meio de entrevistas, questionários, entre outros métodos. De outro, estão os estudos que examinam os efeitos das regras das IPs a partir de análise documental. Este artigo adota a segunda metodologia para avaliar a relação entre desenho institucional e atores beneficiados pelas recomendações aprovadas na $1^{\mathrm{a}} \mathrm{CAP}, 1^{\mathrm{a}}$ ConCidades, $1^{\mathrm{a}} \mathrm{CMA}, 1^{\mathrm{a}} \mathrm{CE}$, $1^{\text {a }}$ CPM e $1^{\text {a }}$ CPIR.

A seleção desses seis processos conferencistas resultou da aplicação de quatro critérios, definidos a partir do objetivo do artigo de avaliar a capacidade de influência dos atores na conferência. Buscou-se controlar o contexto político e institucional de realização da conferência com vistas a maximizar os efeitos esperados do seu desenho sobre a capacidade de influência dos atores em seu resultado final. O contexto político foi controlado pela seleção de conferências realizadas por uma mesma coalizão governativa e por ministérios, cujos ministros eram membros de partidos de esquerda e apresentavam projeto político-participativo alinhado ao do presidente. Além disso, tomou-se o cuidado de selecionar conferências organizadas por atores estatais e não estatais em conjunto, de modo a minimizar os efeitos do não ou do baixo comprometimento e envolvimento de certas categorias com o processo como um todo.

Por fim, observou-se a edição da conferência e selecionaram-se somente os processos inéditos. Buscou-se controlar, em alguma medida, as diferenças na capacidade de atuação dos atores não estatais em conferências e, assim, dos efeitos do aprendizado sobre o resultado final do processo. Em que pese o caráter experimental e, em certa medida, indefinido das conferências selecionadas, a aplicação desse critério tornou-se necessária para reduzir os efeitos positivos do know-how e da expertise de certos grupos em sua capacidade de influenciar o processo conferencista, o que impactaria a análise aqui proposta.

Da aplicação dos critérios supracitados, resultaram as seis conferências examinadas. Todas foram realizadas de forma inédita no primeiro mandato do presidente Lula (2003-2006), foram convocadas por ele e organizadas por ministérios chefiados por atores políticos membros de partidos de esquerda, com a participação direta dos diferentes atores societais envolvidos com a política.

Cada processo conferencista produziu um caderno final de propostas aprovadas, a ser encaminhado ao ministério competente. No total, foram examinadas as 2.536 propostas aprovadas na $1^{\text {a } C A P}, 1^{\text {a }}$ ConCidades, $1^{\text {a }} \mathrm{CMA}, 1^{\text {a }} \mathrm{CE}, 1^{\text {a }} \mathrm{CPM}$ e $1^{\text {a }} \mathrm{CPIR}$, como 
mostra a Tabela 1. Como se observa, a $1^{\text {a }}$ CPIR, $1^{\text {a }}$ CMA e $1^{\text {a }}$ ConCidades aprovaram o maior número de diretrizes, enquanto a $1^{\text {a }} \mathrm{CPM}, 1^{\mathrm{a}} \mathrm{CAP}$ e $1^{\mathrm{a}} \mathrm{CE}$ geraram a menor quantidade ao longo de todo o processo.

\section{Tabela 1}

Total de propostas aprovadas na $1^{\text {a }}$ CAP, 1 a ConCidades, $1^{\text {a }}$ CMA, $1^{\text {a }}$ CE, $1^{\text {a }}$ CPM e $1^{\text {a }}$ CPIR

\begin{tabular}{|l|c|}
\hline Conferência & Total de propostas aprovadas \\
\hline $1^{\text {a } ~ C A P ~}$ & 175 \\
\hline $1^{\text {a }}$ ConCidades & 298 \\
\hline $1^{\text {a } C M A ~}$ & 652 \\
\hline $1^{\text {a } C E}$ & 103 \\
\hline $1^{\text {a } C P M}$ & 253 \\
\hline $1^{\text {a } C P I R ~}$ & 1.055 \\
\hline Total & $\mathbf{2 . 5 3 6}$ \\
\hline
\end{tabular}

Fonte: Formulação própria com base em Brasil (2003a, 2003d, 2003g, 2004b, 2004c, 2005).

Cada proposta foi individualmente classificada segundo o(s) ator(es) de interesse(s), identificado(s) com base na composição da representação das diferentes categorias em cada um dos processos conferencistas examinados (Quadro 1). O Quadro 4 apresenta as categorias consideradas na classificação das propostas finais da $1^{a} \mathrm{CAP}, 1^{a}$ ConCidades, $1^{\text {a } C M A}, 1^{\text {a }} \mathrm{CE}, 1^{\text {a }} \mathrm{CPM}$ e $1^{\mathrm{a}} \mathrm{CPIR}$. Como se vê, em cada processo, as categorias presentes foram consideradas tanto individualmente, quando a proposta interessava apenas a estas, como agrupadamente, em caso de a proposta interessar a duas ou mais categorias compartilhadamente. A análise do conteúdo das propostas aprovadas apontou para essa necessidade, uma vez que, numa mesma proposta, havia demandas de duas ou mais categorias, ora numa mesma sentença, ora em sentenças sequenciais dentro da mesma proposta. 


\section{Quadro 4 \\ Categorias consideradas no âmbito da $1^{\text {a }}$ CAP, $1^{\text {a }}$ ConCidades, $1^{\text {a }}$ CMA, $1^{\text {a }}$ CE, $1^{\text {a }}$ CPM e $1^{\text {a }}$ CPIR}

\begin{tabular}{|c|c|c|}
\hline Conferência & Categorias individuais & Categorias agrupadas \\
\hline $1^{\mathrm{a}} \mathrm{CAP}$ & $\begin{array}{c}\text { Pescadores artesanais e aquicultores } \\
\text { familiares } \\
\text { Empresários da pesca e da } \\
\text { aquicultura } \\
\text { Entidades civis } \\
\text { Governo }\end{array}$ & $\begin{array}{c}\text { Pescadores/aquicultores e empresários } \\
\text { Pescadores/aquicultores e entidades civis } \\
\text { Pescadores artesanais/aquicultores e } \\
\text { governo } \\
\text { Empresários e entidades civis } \\
\text { Empresários e governo } \\
\text { Entidades civis e governo }\end{array}$ \\
\hline $1^{\text {a }}$ ConCidades & $\begin{array}{c}\text { Movimentos urbanos } \\
\text { Entidades civis, acadêmicas e de } \\
\text { pesquisa } \\
\text { Trabalhadores } \\
\text { Empresários } \\
\text { Operadores e concessionários } \\
\text { Governo }\end{array}$ & $\begin{array}{c}\text { Movimentos urbanos e entidades de } \\
\text { pesquisa } \\
\text { Movimentos urbanos e trabalhadores } \\
\text { Movimentos urbanos e empresários } \\
\text { Movimentos urbanos e } \\
\text { operador/concessionário } \\
\text { Movimentos urbanos e governo } \\
\text { Entidades de pesquisa e trabalhadores } \\
\text { Entidades de pesquisa e empresários } \\
\text { Entidades de pesquisa e } \\
\text { operador/concessionário } \\
\text { Entidades de pesquisa e governo } \\
\text { Trabalhadores e empresários } \\
\text { Trabalhadores e operador/concessionário } \\
\text { Trabalhadores e governo } \\
\text { Empresários e operador/concessionário } \\
\text { Empresários e governo } \\
\text { Operador/concessionário e governo }\end{array}$ \\
\hline $1^{\text {a }} \mathrm{CMA}$ & $\begin{array}{c}\text { Movimentos ambientalistas } \\
\text { Entidades civis } \\
\text { Comunidades tradicionais e povos } \\
\text { indígenas } \\
\text { Empresários } \\
\text { Governo }\end{array}$ & $\begin{array}{c}\text { Movimentos ambientalistas e empresários } \\
\text { Movimentos ambientalistas e entidades civis } \\
\text { Movimentos ambientalistas, comunidades } \\
\text { tradicionais e povos indígenas. } \\
\text { Movimentos ambientalistas e governo } \\
\text { Empresários e governo } \\
\text { Entidades civis e governo } \\
\text { Entidades e comunidades e povos indígenas } \\
\text { Entidades e empresários } \\
\text { Comunidades e povos indígenas e } \\
\text { empresários } \\
\text { Comunidades e povos indígenas e governo }\end{array}$ \\
\hline $1^{\mathrm{a}} \mathrm{CE}$ & $\begin{array}{c}\text { Comunidade do esporte profissional } \\
\text { Comunidade do esporte educativo } \\
\text { Comunidade do esporte participativo } \\
\text { Governo }\end{array}$ & $\begin{array}{c}\text { Esporte profissional e educativo } \\
\text { Esporte profissional e participativo } \\
\text { Esporte profissional e governo } \\
\text { Esporte educativo e participativo } \\
\text { Esporte educativo e governo } \\
\text { Esporte participativo e governo }\end{array}$ \\
\hline $1^{\text {a }} \mathrm{CPM}$ & $\begin{array}{c}\text { Movimentos feministas e entidades } \\
\text { civis } \\
\text { Governo } \\
\end{array}$ & $\begin{array}{c}\text { Movimentos feministas, entidades civis e } \\
\text { governo }\end{array}$ \\
\hline $1^{\text {a }}$ CPIR & $\begin{array}{c}\text { Movimentos negros e entidades civis } \\
\text { Movimentos indígenas e entidades } \\
\text { civis } \\
\text { Governo }\end{array}$ & $\begin{array}{c}\text { Movimentos negros, entidades civis e } \\
\text { governo } \\
\text { Movimentos negros, indígenas e entidades } \\
\text { civis } \\
\text { Movimentos indígenas, entidades e governo }\end{array}$ \\
\hline
\end{tabular}

Fonte: Formulação própria com base no Quadro 1. 
$\mathrm{Na}$ política de aquicultura e pesca, as propostas interessavam a pescadores artesanais e aquicultores familiares e/ou a empresários da pesca e aquicultura e/ou a entidades civis com atuação no setor e/ou o governo, enquanto na política urbana as propostas eram de interesse de movimentos urbanos e/ou entidades de pesquisa e/ou de trabalhadores e empresários e/ou de operadores e concessionários de serviços urbanos e/ou do governo. Na política de meio ambiente, por sua vez, as propostas interessavam aos movimentos ambientalistas e/ou entidades civis da área e/ou comunidades tradicionais e povos indígenas e/ou ao setor empresarial e/ou ao governo.

Particularmente em relação à $1^{\text {a }} \mathrm{CE}$ e à $1^{\text {a }}$ CPIR, cuja composição da representação não foi formalmente estabelecida por documentos de referência, consideraram-se as categorias de atores não estatais com atuação já conhecida na política, a saber, a comunidade do esporte profissional, a comunidade do esporte educativo e a comunidade do esporte participativo na política de esportes (Bueno, 2008), e os movimentos negros, indígenas e entidades civis no âmbito da política de promoção da igualdade racial (Ribeiro, 2009). Ademais, para as propostas aprovadas na $1^{\text {a }}$ CPM e na $1^{\text {a }}$ CPIR, não foi considerada a diferenciação entre as demandas de movimentos sociais e de entidades civis pela dificuldade em classificar as propostas de interesse de um e/ou de outro, dada a significativa convergência de discursos e a interação colaborativa entre esses atores ${ }^{3}$. Dessa forma, as propostas aprovadas nos dois processos conferencistas foram classificadas como de interesse seja dos movimentos feministas e entidades civis da área e dos movimentos negros e indígenas e entidades civis da área, seja dos atores governamentais.

A classificação das propostas por categoria interessada baseou-se na resposta à seguinte pergunta: a quem interessa diretamente a aprovação dessa proposta? Para responder a essa pergunta, para cada proposta, identificou-se seu objetivo e buscou-se associá-lo ao discurso e às demandas de alguma(s) categoria(s) no momento de realização da conferência. Nesse sentido, consideraram-se as análises existentes acerca dos interesses, ideias e demandas de cada categoria no âmbito das políticas examinadas (Petinelli, 2014).

Grosso modo, pode-se afirmar que, no âmbito da política de aquicultura e pesca, pescadores e aquicultores familiares, de um lado, e empresários da pesca e aquicultura, de outro, estariam interessados em investimentos financeiros e de infraestrutura nos locais e mercados em que atuam, ao passo que as entidades civis da área demandariam mais ações de proteção à pesca e ao meio ambiente e de incentivo à pesquisa e ao desenvolvimento tecnológico do setor (Castro et al., 2005).

\footnotetext{
$3 \mathrm{Em}$ que pesem os limites analíticos da indiferenciação de categorias para a $1^{a}$ CPM e a $1^{\text {a }}$ CPIR, particularmente, na comparação com as demais conferências, em termos substantivos, essa opção metodológica pouco afeta a análise ou seus resultados, haja vista que as políticas para mulheres e de promoção da igualdade racial caracterizam-se por uma dinâmica política plural e colaborativa, isto é, pela interação de um conjunto diversificado de atores com propostas próximas e, em grande medida, não conflitivas (Petinelli, 2014). Disso seguiria uma atuação cooperativa e reforçadora de demandas no processo conferencista, beneficiando a todas as categorias presentes.
} 
Na política urbana, por sua vez, enquanto movimentos urbanos e entidades civis, acadêmicas e de pesquisa defendiam a ocupação e o uso democráticos e para todos do solo, bem como acesso universal à infraestrutura básica, empresários e operadores e concessionários estavam interessados em políticas de incentivo à construção civil e à produção de bens públicos, independentemente dos critérios e custo social destas (Maricato, 1997, 2000). De modo similar, no âmbito da política ambiental, disputavam a agenda os movimentos ambientalistas, as entidades civis e as comunidades tradicionais e povos indígenas, de um lado, e uma parcela expressiva ${ }^{4}$ do setor empresarial, notadamente, o agronegócio, de outro. Enquanto os primeiros buscavam controlar o uso produtivo do solo com vistas a preservar o meio ambiente, os últimos estavam interessados em políticas mais permissivas e propulsoras do mercado produtivo e industrial (Jacobi, 2003; Vieira e Cader, 2007).

Já na política de esporte, a comunidade do esporte profissional apresentava um discurso em favor de políticas pró-profissionalização do esporte, particularmente, do futebol, ao passo que a comunidade do esporte educativo e a do esporte participativo buscavam investimentos governamentais na área da educação física e do esporte amador e de lazer (Bueno, 2008). Por fim, no que se refere às políticas para mulheres e de promoção da igualdade racial, um discurso convergente, embora não homogêneo, era observado naquele momento: movimentos e entidades civis buscavam, conjuntamente, ações de promoção de direitos e de inclusão social, econômica e política das mulheres (Costa, 2005), dos negros e dos indígenas (Ribeiro, 2009).

O Quadro 5 traz exemplos da classificação das propostas aprovadas na $1^{a}$ CAP, $1^{a}$ ConCidades, $1^{\text {a } C M A}, 1^{\text {a }} \mathrm{CE}, 1^{\text {a }}$ CPM e $1^{\text {a }}$ CPIR por categoria(s) de interesse. Em cada proposta apresentada, buscou-se identificar a(s) categoria(s) beneficiada(s), bem como destacar (em itálico) o objetivo da proposta, com vistas a facilitar a compreensão do leitor acerca da relação entre objetivo e categoria(s) interessada(s).

\footnotetext{
${ }^{4}$ Cabe ressalvar que há uma parcela, embora pequena, do setor empresarial brasileiro que tem apresentado um discurso de pró-conservação e sustentabilidade ambiental, que se aproxima e até se confunde com o discurso de movimentos e entidades ambientalistas (Silva-Sánchez, 1999).
} 


\section{Quadro 5 \\ Exemplos de propostas de interesse de categorias separadas e agrupadas por conferência}

\begin{tabular}{|c|c|c|}
\hline Conferência & Categoria(s) & Proposta \\
\hline $1^{\text {a }}$ CAP & $\begin{array}{l}\text { Atores societais } \\
\text { (pescadores, } \\
\text { aquicultores } \\
\text { familiares, } \\
\text { empresários e } \\
\text { entidades civis) }\end{array}$ & $\begin{array}{l}\text { Incentivo à criação de conselhos municipais, estaduais, } \\
\text { fóruns microrregionais e câmaras técnicas locais de } \\
\text { aquicultura, pesca e pesquisa, para que, em conjunto } \\
\text { com o Conselho Nacional da Aquicultura e Pesca, } \\
\text { integrem as entidades representativas desses setores } \\
\text { na construção democrática das políticas de } \\
\text { desenvolvimento em todas as esferas governamentais. }\end{array}$ \\
\hline $1^{\text {a }}$ ConCidades & Movimentos urbanos & $\begin{array}{l}\text { A gestão democrática deve reconhecer a autonomia } \\
\text { dos movimentos sociais, sem discriminação, e estar } \\
\text { sempre comprometida com o direito universal a } \\
\text { educação, saúde, moradia, trabalho, previdência } \\
\text { social, transporte, meio ambiente saudável, cultura e } \\
\text { lazer. }\end{array}$ \\
\hline $1^{\text {a }}$ CMA & Governo & $\begin{array}{l}\text { Viabilizar o pacto federativo, fortalecendo, sobretudo, } \\
\text { a comissão tripartite como um dos grandes fóruns para } \\
\text { a construção do Pacto Ambiental do país, por meio da } \\
\text { instalação e da consolidação de comissões tripartites } \\
\text { nos estados e bipartite no Distrito Federal, envolvendo } \\
\text { representantes dos órgãos ambientais da União, dos } \\
\text { estados e dos municípios. }\end{array}$ \\
\hline $1^{a} \mathrm{CE}$ & Esporte profissional & $\begin{array}{l}\text { Detectar e desenvolver talentos esportivos em } \\
\text { potencial e aprimorar o desempenho de atletas e } \\
\text { paratletas de rendimento; }\end{array}$ \\
\hline $1^{\text {a }} \mathrm{CPM}$ & $\begin{array}{l}\text { Movimentos } \\
\text { feministas e } \\
\text { entidades civis }\end{array}$ & $\begin{array}{l}\text { Estabelecer estratégias que promovam equilíbrio de } \\
\text { poder entre mulheres e homens, em termos de } \\
\text { recursos econômicos, direitos legais, participação } \\
\text { política e relações interpessoais. }\end{array}$ \\
\hline $1^{\text {a }}$ CPIR & $\begin{array}{l}\text { Movimentos negros, } \\
\text { entidades civis com } \\
\text { essa bandeira e } \\
\text { governo }\end{array}$ & $\begin{array}{l}\text { Implementar, no serviço público, o programa de } \\
\text { combate ao racismo institucional. }\end{array}$ \\
\hline
\end{tabular}

Fonte: Formulação própria com base em Brasil (2003a, 2003d, 2003g, 2004b, 2004c, 2005).

A seguir, apresentam-se os resultados obtidos a partir da análise das propostas aprovadas na $1^{\text {a } C A P}, 1^{\text {a }}$ ConCidades, $1^{\text {a } C M A}, 1^{\text {a }} \mathrm{CE}, 1^{\text {a }}$ CPM e $1^{\text {a }}$ CPIR e se avalia se e em que medida o conteúdo dessas propostas reflete o grau de inclusão política gerado pelo desenho de cada conferência.

Constatações acerca da relação entre desenho institucional e propostas aprovadas

O desenho institucional da $1^{\text {a }}$ CAP, $1^{\text {a }}$ ConCidades, $1^{\text {a }}$ CMA $, 1^{\text {a }} \mathrm{CE}, 1^{\text {a }}$ CPM e $1^{\text {a }}$ CPIR estabeleceu, por meio das regras quanto às dinâmicas representativa e deliberativa aplicadas, a capacidade de influência de cada categoria presentes nas conferências sobre as propostas finais aprovadas. Como visto na seção sobre metodologia de pesquisa, a $1^{a}$ CAP, $1^{\text {a }}$ ConCidades, $1^{\text {a }}$ CMA e $1^{\text {a }}$ CPM regulamentaram a composição da representação, assegurando a participação de todas as categorias envolvidas com a respectiva política ao 
longo do processo. Já a $1^{\text {a }}$ CE e a $1^{\text {a }}$ CPIR não definiram critérios de seleção dos delegados, o que pode ter gerado sub ou sobrerrepresentação de alguma categoria envolvida com a política.

Somado a isso, a $1^{\text {a }}$ ConCidades, $1^{\text {a }}$ CE e $1^{\text {a }}$ CPIR não estabeleceram regras claras quanto ao processo de discussão e de tomada de decisão nos encontros. Por hipótese, tal dinâmica deliberativa pode ter tanto prejudicado e excluído como favorecido certas narrativas representadas por um número maior de delegados presentes nos espaços de debate e tomada de decisão dessas conferências.

A Tabela 2 mostra a quantidade de propostas aprovadas na $1^{\text {a } C A P,} 1^{\text {a }}$ ConCidades, $1^{\text {a }}$ CMA, $1^{\text {a }} \mathrm{CE}, 1^{\text {a }}$ CPM e $1^{\text {a }}$ CPIR de interesse direto das categorias consideradas individual e agrupadamente. Como se constata, quase $60 \%$ do total de propostas aprovadas beneficiava diretamente algum segmento específico presente na conferência. Dentre os encontros analisados, a $1^{\text {a } C A P}, 1^{\text {a }}$ ConCidades, $1^{\text {a }}$ CPM e $1^{\text {a }}$ CPIR produziram o maior porcentual de propostas de interesse de uma comunidade particular de atores, enquanto da $1^{\text {a }}$ CMA e $1^{\text {a }}$ CE resultou um conjunto maior de propostas de interesse de duas ou mais categorias compartilhadamente.

Tabela 2

Total de propostas aprovadas de interesse direto de categorias individuais e agrupadas por conferência examinada (\%)

\begin{tabular}{|l|c|c|c|c|c|c|c|}
\hline Propostas aprovadas & $\begin{array}{c}\mathbf{1}^{\mathbf{a}} \\
\text { CAP }\end{array}$ & $\begin{array}{c}\mathbf{1}^{\text {a }} \\
\text { ConCidades }\end{array}$ & $\begin{array}{c}\mathbf{1}^{\mathbf{a}} \\
\text { CMA }\end{array}$ & $\mathbf{1}^{\text {a }} \mathbf{C E}$ & $\begin{array}{c}\mathbf{1}^{\mathbf{a}} \\
\mathbf{C P M}\end{array}$ & $\begin{array}{c}\mathbf{1}^{\mathbf{a}} \\
\text { CPIR }\end{array}$ & Total \\
\hline Categorias individuais & 91 & 189 & 300 & 42 & 239 & 612 & 1.473 \\
& $(52,0)$ & $(63,4)$ & $(46,0)$ & $(41,0)$ & $(94,5)$ & $(58,0)$ & $(58,0)$ \\
\hline \multirow{2}{*}{ Categorias agrupadas } & 84 & 109 & 352 & 61 & 14 & 443 & 1.063 \\
& $(48,0)$ & $(36,5)$ & $(54,0)$ & $(59,0)$ & $(5,5)$ & $(42,0)$ & $(42,0)$ \\
\hline \multirow{2}{*}{ Total } & $\mathbf{1 7 5}$ & $\mathbf{2 9 8}$ & $\mathbf{6 5 2}$ & $\mathbf{1 0 3}$ & $\mathbf{2 5 3}$ & $\mathbf{1 . 0 5 5}$ & $\mathbf{2 . 5 3 6}$ \\
& $\mathbf{( 1 0 0 )}$ & $\mathbf{( 1 0 0 )}$ & $\mathbf{( 1 0 0 )}$ & $\mathbf{( 1 0 0 )}$ & $\mathbf{( 1 0 0 )}$ & $\mathbf{( 1 0 0 )}$ & $\mathbf{( 1 0 0 )}$ \\
\hline
\end{tabular}

Fonte: Formulação própria com base no caderno final de cada conferência (Brasil, 2003a, 2003d, 2003g, 2004b, 2004c, 2005).

Desagregando esses resultados por categoria individualmente beneficiada, o que se observa é uma variação expressiva em relação à capacidade de influência de cada categoria no resultado final da respectiva conferência, embora as organizações da sociedade civil tenham sido amplamente mais beneficiadas pelas propostas aprovadas em todas elas (Tabela 3): 
Tabela 3

Total de propostas aprovadas de interesse direto de cada categoria considerada individualmente por conferência examinada (\%)

\begin{tabular}{|c|c|c|}
\hline Conferência & Categoria & Propostas aprovadas \\
\hline \multirow{4}{*}{$1^{\text {a }}$ CAP } & Pescadores artesanais e aquicultores familiares & $\begin{array}{c}56 \\
(61,5)\end{array}$ \\
\hline & Empresários da pesca e da aquicultura & $\begin{array}{c}10 \\
(11) \\
\end{array}$ \\
\hline & Organizações civis com atuação no setor & $\begin{array}{c}14 \\
(15,4)\end{array}$ \\
\hline & Governo & $\begin{array}{c}11 \\
(12,1)\end{array}$ \\
\hline Total parcial & & $\begin{array}{c}91 \\
(52)\end{array}$ \\
\hline \multirow{6}{*}{$1^{\text {a }}$ ConCidades } & Movimentos urbanos & $\begin{array}{c}93 \\
(49,2)\end{array}$ \\
\hline & Organizações civis, acadêmicas e de pesquisa & $\begin{array}{l}17 \\
(9)\end{array}$ \\
\hline & Trabalhadores & $\begin{array}{c}2 \\
(1,1)\end{array}$ \\
\hline & Empresários & $\begin{array}{c}4 \\
(2,1)\end{array}$ \\
\hline & Operadores e concessionários & $\begin{array}{c}15 \\
(7,9)\end{array}$ \\
\hline & Governo & $\begin{array}{c}58 \\
(30,7)\end{array}$ \\
\hline Total parcial & & $\begin{array}{c}189 \\
(63,4)\end{array}$ \\
\hline \multirow{5}{*}{$1^{\text {a }}$ CMA } & Movimentos ambientalistas & $\begin{array}{c}135 \\
(45,0) \\
\end{array}$ \\
\hline & Organizações civis & $\begin{array}{c}25 \\
(8,4)\end{array}$ \\
\hline & Comunidades tradicionais e povos indígenas & $\begin{array}{c}28 \\
(9,4)\end{array}$ \\
\hline & Empresários & $\begin{array}{c}59 \\
(19,6)\end{array}$ \\
\hline & Governo & $\begin{array}{c}53 \\
(17,6)\end{array}$ \\
\hline Total parcial & & $\begin{array}{c}300 \\
(46,0)\end{array}$ \\
\hline \multirow{4}{*}{$1^{\mathrm{a}} \mathrm{CE}$} & Comunidade do esporte profissional & $\begin{array}{c}12 \\
(28,6)\end{array}$ \\
\hline & Comunidade do esporte educativo & $\begin{array}{c}9 \\
(21,4)\end{array}$ \\
\hline & Comunidade do esporte participativo & $\begin{array}{c}7 \\
(16,7)\end{array}$ \\
\hline & Governo & $\begin{array}{c}14 \\
(33,3)\end{array}$ \\
\hline Total parcial & & $\begin{array}{c}42 \\
(41,0)\end{array}$ \\
\hline \multirow{2}{*}{$1^{\text {a }}$ CPM } & Movimentos feministas e organizações civis & $\begin{array}{c}175 \\
(73,2)\end{array}$ \\
\hline & Governo & $\begin{array}{c}64 \\
(26,8)\end{array}$ \\
\hline Total parcial & & $\begin{array}{c}239 \\
(94,5)\end{array}$ \\
\hline
\end{tabular}


A QUEM SERVEM AS CONFERÊNCIAS DE POLÍTICAS PÚBLICAS?

\begin{tabular}{|l|c|c|}
\hline Conferência & Categoria & Propostas aprovadas \\
\hline \multirow{3}{*}{$1^{\text {a }}$ CPIR } & Movimentos negros e organizações civis & 416 \\
& Movimentos indígenas e organizações civis & $(68)$ \\
\cline { 2 - 3 } & Governo & $(120,6)$ \\
\cline { 2 - 3 } & & 76 \\
\hline \multirow{2}{*}{ Total parcial } & & $(12,4)$ \\
\hline Total geral & $\mathbf{6 1 2}$ \\
\hline
\end{tabular}

Fonte: Formulação própria com base no caderno final de cada conferência (Brasil, 2003a, 2003d, 2003g, 2004b, 2004c, 2005).

$\mathrm{Na} 1^{\text {a }} \mathrm{CPM}$ e $1^{\mathrm{a}} \mathrm{CPIR}$, que reuniram exclusivamente atores governamentais $\mathrm{e}$ sociais, a maior porcentagem de propostas aprovadas, cerca de $90 \%$, interessava diretamente aos movimentos sociais e às organizações da sociedade civil. Semelhantemente, nos encontros que envolveram atores de mercado e da sociedade civil, isto é, a $1^{\text {a }} \mathrm{CAP}, 1^{\text {a }}$ ConCidades, $1^{\mathrm{a}} \mathrm{CMA}$ e $1^{\mathrm{a}} \mathrm{CE}$, as propostas aprovadas eram de interesse, em maior medida, de atores sociais, salvo no caso da $1^{\text {a }} \mathrm{CE}$. Do total de propostas aprovadas de interesse de apenas uma categoria na $1^{\text {a }}$ CAP, $61,5 \%$ interessavam à comunidade de pescadores artesanais e aquicultores familiares e 15,4\%, às organizações civis com atuação no setor. De modo similar, na $1^{a} \mathrm{CMA}$ e na $1^{\mathrm{a}}$ ConCidades, em torno de $60 \%$ das propostas eram de interesse direto da sociedade civil, composta por movimentos sociais e organizações civis com atuação nas áreas.

De modo distinto, o governo e as comunidades do esporte repartiram, de forma bem equilibrada, as propostas aprovadas na $1^{\mathrm{a}} \mathrm{CE}$, sendo a diferença de até sete propostas entre eles. Ademais, a $1^{\text {a }}$ CE foi o único processo no qual o governo mais se beneficiou individualmente das propostas aprovadas, sendo mais de $33 \%$ delas de interesse particular desse setor. Na $1^{a}$ ConCidades, o governo também aprovou mais de $30 \%$ de propostas de seu interesse, mas não foi a categoria mais beneficiada no processo; os movimentos urbanos influenciaram de modo mais expressivo, com quase $50 \%$ de propostas aprovadas de seu interesse exclusivo. Nas demais conferências, o setor público foi o segmento menos beneficiado individualmente, como mostra a Tabela 3.

Resultados semelhantes quanto à capacidade de influência dos diferentes grupos societais e governamentais sobre as propostas aprovadas na $1^{\text {a }}$ CAP, $1^{\text {a }}$ ConCidades, $1^{\text {a }}$ CMA, $1^{\text {a }} \mathrm{CE}, 1^{\text {a }}$ CPM e $1^{\text {a }}$ CPIR são observados ao se analisarem as propostas de interesse direto de duas ou mais categorias conjuntamente. Como se constata pela Tabela 4, as categorias mais proeminentes individualmente também aparecem como as principais beneficiadas de propostas que interessavam a dois ou mais grupos compartilhadamente.

$\mathrm{Na} 1^{\mathrm{a}} \mathrm{CAP}, 1^{\mathrm{a}}$ ConCidades, $1^{\mathrm{a}} \mathrm{CMA}, 1^{\mathrm{a}} \mathrm{CPM}$ e $1^{\mathrm{a}} \mathrm{CPIR}$, os atores sociais conquistaram o maior percentual de propostas aprovadas de seu interesse exclusivo e em conjunto com outra categoria. Do total de propostas coletivas aprovadas, $90 \%$ ou mais beneficiavam diretamente os pescadores artesanais, os movimentos urbanos e a sociedade 
civil no âmbito da política de meio ambiente, das políticas para mulheres e de promoção da igualdade racial. Na $1^{\text {a }} \mathrm{CE}$, por sua vez, a maior proporção de propostas aprovadas $(78,7 \%)$ interessava a todos indiscriminadamente e as demais interessavam, em maior medida, à comunidade de esporte profissional e/ou de esporte educativo, como observado para as propostas de interesse exclusivo de apenas uma categoria (Tabela 3).

Tabela 4

Total de propostas aprovadas de interesse direto de duas ou mais categorias por conferência examinada (\%)

\begin{tabular}{|c|c|c|}
\hline Conferência & Categoria & Propostas aprovadas \\
\hline \multirow{5}{*}{$1^{\text {a }}$ CAP } & Pescadores/aquicultores e empresários & $\begin{array}{c}60 \\
(71,4) \\
\end{array}$ \\
\hline & Pescadores/aquicultores e organizações civis & $\begin{array}{c}5 \\
(6,0)\end{array}$ \\
\hline & Empresários e governo & $\begin{array}{c}1 \\
(1,2)\end{array}$ \\
\hline & Organizações civis e governo & $\begin{array}{c}1 \\
(1,2)\end{array}$ \\
\hline & Todos & $\begin{array}{c}17 \\
(20,2)\end{array}$ \\
\hline Total parcial & & $\begin{array}{c}84 \\
(48,0)\end{array}$ \\
\hline \multirow{11}{*}{$1^{\text {a }}$ ConCidades } & Movimentos urbanos e organizações de pesquisa & $\begin{array}{c}6 \\
(5,5) \\
\end{array}$ \\
\hline & Movimentos urbanos e trabalhadores & $\begin{array}{c}1 \\
(0,9)\end{array}$ \\
\hline & Movimentos urbanos e empresários & $\begin{array}{c}10 \\
(9,2)\end{array}$ \\
\hline & Movimentos urbanos e operador/concessionário & $\begin{array}{c}23 \\
(21,1)\end{array}$ \\
\hline & Movimentos urbanos e governo & $\begin{array}{c}10 \\
(9,2)\end{array}$ \\
\hline & Organizações de pesquisa e trabalhadores & $\begin{array}{c}2 \\
(1,8)\end{array}$ \\
\hline & Organizações de pesquisa e empresários & $\begin{array}{c}3 \\
(2,8)\end{array}$ \\
\hline & Empresários e operador/concessionário & $\begin{array}{c}1 \\
(0,9) \\
\end{array}$ \\
\hline & Empresários e governo & $\begin{array}{c}1 \\
(0,9)\end{array}$ \\
\hline & Operador/concessionário e governo & $\begin{array}{c}6 \\
(5,5) \\
\end{array}$ \\
\hline & Todos & $\begin{array}{c}46 \\
(42,2) \\
\end{array}$ \\
\hline Total parcial & & $\begin{array}{c}109 \\
(36,5)\end{array}$ \\
\hline
\end{tabular}




\begin{tabular}{|c|c|c|}
\hline Conferência & Categoria & Propostas aprovadas \\
\hline \multirow{11}{*}{$1^{\mathrm{a}} \mathrm{CMA}$} & Movimentos ambientalistas e empresários & $\begin{array}{c}30 \\
(8,4) \\
\end{array}$ \\
\hline & Movimentos ambientalistas e governo & $\begin{array}{c}35 \\
(10,0)\end{array}$ \\
\hline & Movimentos ambientalistas e comunidades & $\begin{array}{c}17 \\
(5,0)\end{array}$ \\
\hline & Movimentos ambientalistas e entidades civis & $\begin{array}{c}146 \\
(41,4)\end{array}$ \\
\hline & Comunidades e entidades civis & $\begin{array}{c}10 \\
(3,0)\end{array}$ \\
\hline & Entidades civis e governo & $\begin{array}{c}6 \\
(1,6)\end{array}$ \\
\hline & Empresários e governo & $\begin{array}{c}3 \\
(0,8)\end{array}$ \\
\hline & Atores sociais & $\begin{array}{c}47 \\
(13,2)\end{array}$ \\
\hline & Atores sociais e governo & $\begin{array}{c}10 \\
(3,0)\end{array}$ \\
\hline & Atores societais & $\begin{array}{c}20 \\
(5,6)\end{array}$ \\
\hline & Todos & $\begin{array}{c}28 \\
(8,0)\end{array}$ \\
\hline Total parcial & & $\begin{array}{c}352 \\
(54,0)\end{array}$ \\
\hline \multirow{4}{*}{$1^{a} \mathrm{CE}$} & Esporte profissional e educativo & $\begin{array}{c}6 \\
(9,8) \\
\end{array}$ \\
\hline & Esporte profissional e participativo & $\begin{array}{c}1 \\
(1,6) \\
\end{array}$ \\
\hline & Esporte educativo e participativo & $\begin{array}{c}6 \\
(9,8) \\
\end{array}$ \\
\hline & Todos & $\begin{array}{c}48 \\
(78,7)\end{array}$ \\
\hline Total parcial & & $\begin{array}{c}61 \\
(59,0)\end{array}$ \\
\hline $1^{\mathrm{a}} \mathrm{CPM}$ & Sociedade civil e governo & $\begin{array}{c}14 \\
(5,5) \\
\end{array}$ \\
\hline Total parcial & & $\begin{array}{c}14 \\
(5,5)\end{array}$ \\
\hline \multirow{2}{*}{$1^{\text {a }}$ CPIR } & $\begin{array}{c}\text { Movimentos negros e indígenas e } \\
\text { organizações civis }\end{array}$ & $\begin{array}{c}415 \\
(93,7)\end{array}$ \\
\hline & $\begin{array}{l}\text { Movimentos negros e indígenas e } \\
\text { organizações civis e governo }\end{array}$ & $\begin{array}{c}28 \\
(6,3)\end{array}$ \\
\hline Total parcial & & $\begin{array}{c}443 \\
(42,0)\end{array}$ \\
\hline Total geral & & $\begin{array}{l}1.063 \\
(42,0)\end{array}$ \\
\hline
\end{tabular}

Fonte: Formulação própria com base no caderno final de cada conferência (Brasil, 2003a, 2003d, 2003g, 2004b, 2004c, 2005).

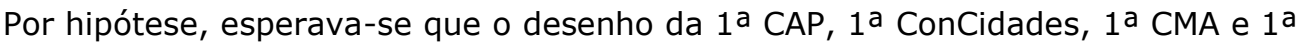
CPM gerasse capacidade de influência desigual dos atores societais, devido ao favorecimento da representação de certos grupos, respectivamente, dos pescadores artesanais e aquicultores familiares, dos movimentos urbanos, dos movimentos 
ambientalistas e dos movimentos feministas e organizações civis alinhadas politicamente a estes. Igualmente, acreditava-se que a ausência de regras quanto à dinâmica representativa e deliberativa na $1^{\text {a }}$ CE e $1^{\text {a }}$ CPIR traduzir-se-ia na maior capacidade de influência dos grupos politicamente mais influentes de cada área naquele momento, a saber, a comunidade de esporte profissional e os movimentos negros (Quadro 3).

Os resultados das Tabelas 3 e 4 corroboram, em grande medida, essas hipóteses. Como constatado, os atores mais bem representados e politicamente mais influentes na $1^{\text {a } C A P}, 1^{\text {a }}$ ConCidades, $1^{\text {a }}$ CMA, $1^{\text {a }}$ CPM e $1^{\text {a }}$ CPIR se beneficiaram, em maior medida, das propostas aprovadas tanto de interesse exclusivo como de interesse compartilhado com outro(s) ator(es). Já no que concerne à $1^{\mathrm{a}} \mathrm{CE}$, cujo processo conferencista não estabeleceu regras quanto à dinâmica representativa e deliberativa, o que se observa é uma capacidade de influência mais bem distribuída e mais equilibrada e uma maior produção e aprovação de recomendações de interesse de dois ou mais grupos (59\% do total de propostas aprovadas).

O desenho da $1^{\text {a }}$ CAP assegurou a participação na primeira etapa (estadual) de 3 delegados por organização civil da pesca e aquicultura, dentre os quais 1 para cada 5 dos delegados presentes foi escolhido para o encontro nacional. Como o número de organizações de pescadores artesanais e aquicultores familiares, bem como o de outras instituições civis com atuação no setor, excede, em muito, o de organizações patronais e empresariais nessa política (Petinelli, 2014), as regras quanto à representação favoreceram a participação dos primeiros em relação aos segundos e, assim, a maior aprovação de propostas de interesse de pescadores artesanais, aquicultores familiares e demais organizações com atuação no setor.

Semelhantemente, o desenho da $1^{\text {a }}$ ConCidades beneficiou, em maior medida, duas categorias: os movimentos urbanos, que representavam $42 \%$ do total de delegados societais, e o governo, com $40 \%$ do total de delegados da conferência. Essas foram as duas categorias com maior proporção de propostas aprovadas ao final do processo, tanto individual como conjuntamente, como mostrado nas Tabelas 3 e 4.

Da dinâmica representativa plural da $1^{\text {a }}$ CMA e da $1^{\text {a }}$ CPM, também resultou um conjunto mais extenso de propostas finais de interesse dos atores sociais representados em maior proporção nos encontros. O desenho da $1^{\text {a }}$ CMA assegurou $62,5 \%$ das vagas de delegados não estatais para representantes da sociedade civil, ao passo que a $1^{\text {a }} \mathrm{CPM}$ destinou $60 \%$ destas para a sociedade civil. Esse conjunto de atores sociais conquistou, em ambos os processos, mais de $60 \%$ do total das propostas finais de interesse exclusivo de uma categoria (Tabela 3 ) ou de interesse compartilhado de duas ou mais categorias (Tabela 4).

Por outro lado, na ausência de regras claras de representação, como no caso da $1^{\text {a }} \mathrm{CE}$ e $1^{\mathrm{a}} \mathrm{CPIR}$, os resultados foram distintos. Da $1^{\mathrm{a}} \mathrm{CE}$, resultou um número mais expressivo de propostas de interesse de categorias agrupadas, ao passo que na $1^{\text {a }}$ CPIR as categorias individuais aprovaram um número maior de propostas de seu interesse 
exclusivo. Enquanto na $1^{\text {a }} \mathrm{CE}$ a ausência de regras produziu certo equilíbrio na capacidade de influência das categorias individuais e a aprovação de parcela expressiva de propostas em benefício de duas ou mais categorias, na $1^{\text {a }}$ CPIR a falta de regulamentação da dinâmica representativa possibilitou o predomínio de propostas em benefício exclusivo e conjunto de atores sociais, os quais usualmente participam, em maior proporção, nos processos conferencistas.

Esses resultados distintos, a partir de desenhos institucionais semelhantes, parecem decorrer, por sua vez, da dinâmica política nessas áreas, isto é, do padrão de interação e atuação das diferentes categorias no âmbito da política de esportes e das políticas de promoção da igualdade racial. Como mostrado por Petinelli (2014), a dinâmica política afeta o grau de incorporação das propostas aprovadas nas conferências nos programas da respectiva política setorial. Embora a autora não analise a relação entre desenho institucional das conferências e atores beneficiados pelas propostas nelas aprovadas, os resultados aqui obtidos para a $1^{\text {a }}$ CE e a $1^{\text {a }}$ CPIR sugerem que, não havendo regras definidas de representação e de deliberação, a dinâmica política também impacta, em alguma medida, o resultado final da conferência. A ausência de critérios para seleção e composição de delegados no processo conferencista, bem como de regulamentação do processo deliberativo ao longo da conferência, criaria o ambiente institucional propício para a replicação da configuração política da respectiva área, levando à sub e/ou sobrerrepresentação e/ou exclusão e/ou equilíbrio de forças políticas no processo conferencista.

No ano de realização da $1^{\text {a }} \mathrm{CE}$, três comunidades disputavam a atenção e as ações governamentais na política de esporte: a comunidade do esporte profissional, a do esporte educativo e a do esporte participativo ou de lazer. Até aquele momento, o governo favorecera, historicamente, o esporte de alto rendimento e, portanto, os grupos a ele vinculados (Petinelli, 2014). A $1^{\text {a }}$ CE consistiu, assim, em uma oportunidade de vocalização de demandas e influência política para a comunidade do esporte educativo e a do esporte participativo, até então excluídas dos espaços deliberativos e dos programas governamentais. Nesse processo, as três comunidades disputaram as propostas e alcançaram, de forma equilibrada, seu objetivo (Tabelas 3 e 4), refletindo a dinâmica política competitiva da área naquele momento.

Por sua vez, no ano de realização da $1^{\text {a }}$ CPIR, em 2005, a política nacional de promoção da igualdade racial era inédita e havia ganhado corpo pela atuação conjunta de uma ampla e diversificada rede de atores sociais, organizados em torno dos movimentos negros e indígenas e de organizações civis alinhadas politicamente a estes (Petinelli, 2014). Com essa dinâmica política, a ausência de regras quanto à composição da representação na $1^{\text {a }}$ CPIR não teria impactado negativamente a capacidade de influência dos atores sociais nas propostas aprovadas; pelo contrário, ela possibilitou que cerca de $90 \%$ destas fossem de interesse exclusivo ou compartilhado dos movimentos negros e indígenas e das organizações civis com atuação na área. 


\section{Considerações finais}

As conferências de políticas públicas têm servido enquanto espaços de inclusão de novas vozes no processo de discussão de políticas. Delas tem resultado um conjunto de propostas para as instituições competentes, que expressam, em menor ou maior medida, as demandas e os interesses das categorias nelas presentes. A capacidade de influência de cada setor é constrangida, porém, pelo desenho institucional do encontro, o qual pode tanto favorecer como limitar a participação e as oportunidades de decisão dos atores societais ao longo do processo.

Este artigo buscou lançar luz à relação entre desenho institucional e atores beneficiados pelas propostas aprovadas em conferências, a partir da análise de seis processos inéditos: a $1^{\text {a }}$ CAP, a $1^{\text {a }}$ ConCidades, a $1^{\text {a }}$ CMA, a $1^{\text {a }}$ CE, a $1^{\text {a }}$ CPM e a $1^{\text {a }}$ CPIR. Partiu-se da hipótese de que o desenho institucional das conferências, observado a partir da dinâmica representativa e deliberativa estabelecida em seu Regimento Interno, determinaria quem se beneficia das propostas aprovadas, o que, por sua vez, impactaria a capacidade de inclusão política do arranjo, dada pela combinação entre pluralidade de representação e processo deliberativo democrático.

Dos seis processos conferencistas examinados, esperavam-se resultados pouco representativos e uma capacidade de influência desigual dos atores não estatais nas propostas aprovadas ao final do processo. O desenho da $1^{\text {a } C A P,} 1^{\text {a }}$ ConCidades, $1^{\text {a }}$ CMA e $1^{\text {a }}$ CPM reforçaria o favorecimento do RI a certos grupos, o que, por sua vez, geraria um processo plural, mas menos representativo. Semelhantemente, a ausência de regras quanto à dinâmica representativa e deliberativa na $1^{\text {a }}$ CE e $1^{\text {a }}$ CPIR acarretaria, por hipótese, um processo mais elitizado e com resultados menos representativos, traduzido na maior capacidade de influência dos grupos politicamente mais influentes de cada área.

Para testar tal suposição, cada proposta aprovada na $1^{a}$ CAP, $1^{a}$ ConCidades, $1^{a}$ CMA, $1^{\text {a }}$ CE, $1^{\text {a }}$ CPM e $1^{\text {a }}$ CPIR foi classificada segundo a(s) categoria(s) à(s) qual(is) diretamente interessava com base em seu objetivo e nos discursos e demandas de cada categoria no momento de realização da conferência. No total, foram examinadas 2.536 propostas aprovadas.

Dessa análise, constatou-se que o desenho institucional impacta, em certa medida, a capacidade de influência dos atores presentes nas conferências. Os atores mais representados na $1^{\text {a }}$ CAP, $1^{\text {a }}$ ConCidades, $1^{\text {a }}$ CMA e $1^{\text {a }}$ CPM se beneficiaram, em maior medida, das propostas aprovadas tanto de interesse exclusivo como de interesse compartilhado com outro(s) ator(es). Quando havia regras claras de representação, a conferência produziu um número mais expressivo de propostas em benefício das categorias com maior representação assegurada nesta. Na $1^{\text {a }}$ CAP, foram beneficiados os pescadores artesanais e aquicultores familiares, seguidos pelas organizações civis com atuação no setor. Na $1^{\text {a }}$ ConCidades, os movimentos urbanos e o governo, que foram os mais representados, aprovaram o maior número de propostas de seu interesse exclusivo e 
compartilhado. A dinâmica representativa regulamentada, somada à inexistência de regras formais quanto ao processo deliberativo, consolidou o favorecimento desses atores na aprovação de propostas de seu interesse ao longo da $1^{\text {a }}$ ConCidades. Já na $1^{\text {a }}$ CMA e na $1^{\text {a }}$ CPM, a representação da sociedade civil foi privilegiada pelas regras institucionais, 0 que resultou no número maior de propostas de seu interesse aprovadas ao final de ambos os processos.

Por outro lado, na ausência de regras claras de representação e deliberação, como no caso da $1^{\text {a }}$ CE e da $1^{\text {a }}$ CPIR, a capacidade de influência dos atores estatais e não estatais na conferência refletiu o nível de influência política destes na respectiva política. A disputa por atenção e ações governamentais entre as comunidades do esporte profissional, educativo e participativo na política de esporte se traduziu em uma distribuição mais equilibrada das propostas aprovadas na $1^{a}$ CE. No âmbito da política de promoção da igualdade racial, por seu turno, a falta de regulamentação da dinâmica representativa e deliberativa da $1^{\text {a }}$ CPIR resultou em um número expressivamente maior de propostas em benefício exclusivo e compartilhado de atores sociais, os quais atuavam cooperativamente entre si e com os atores governamentais naquele momento (Petinelli, 2014).

De modo geral, portanto, é possível sugerir, pela análise aqui empregada, que a capacidade dos atores de influenciar as propostas aprovadas em conferências é afetada pelo seu desenho institucional, notadamente, pela combinação de dinâmica representativa com dinâmica deliberativa. Quando há regras claras de seleção e composição de delegados e uma dinâmica deliberativa que reforça o cenário representativo criado, a capacidade de influência dos atores tende a corresponder à proporção em que são representados no processo conferencista. Na ausência de regras de representação e deliberação, por outro lado, a capacidade de influência dos atores na conferência tende a refletir o nível de influência política destes na área de política em discussão.

Enquanto espaços potencialmente plurais e democráticos, as conferências podem gerar resultados, muitas vezes, pouco representativos dessa diversidade, em decorrência da dinâmica representativa e deliberativa que estabelecem. Em contextos políticos menos permeáveis à participação, a relação entre desenho institucional e capacidade de influência dos atores torna-se ainda mais relevante, dados os potenciais ganhos inclusivos da implementação de arranjos participativos no bojo do processo de políticas públicas.

Viviane Petinelli - Pós-doutoranda em ciência política pelo Programa de Pós-Graduação em Ciência Política da Universidade Federal de Minas Gerais. E-mail: <vpetinelli@hotmail.com>. 


\section{Referências bibliográficas}

ABERS, R. "Overcoming the dilemmas of participatory democracy: the participatory budget policy in Porto Alegre, Brazil". In: XXII international Congress of the Latin American Studies Association. Miami, Florida, 16-18 march, 2000.

. "Practicing radical democracy. Lessons from Brazil". DISP, vol. 147, n 4, 2001.

ALMEIDA, D. R. Representação política e conferências: estabelecendo uma agenda de pesquisa. In: AVRITZER, L.; SouzA, C. H. L. (orgs.). Conferências nacionais: atores, dinâmicas e efetividade. Brasília: Ipea, 2013.

AVRITZER, L. "Instituições participativas e desenho institucional: algumas considerações sobre a variação da participação no Brasil democrático". Opinião Pública, Campinas, vol. 14, n 1, p. 43-64, 2008.

2009.

. Participatory institutions in democratic Brazil. Baltimore: Jonhs Hopkins University Press,

. Conferências nacionais: ampliando e redefinindo os padrões de participação social no Brasil. In: AVRITZER, L.; SouzA, C. H. L. (orgs.). Conferências nacionais: atores, dinâmicas e efetividade. Brasília: Ipea, 2013.

Avritzer, L.; NAvarro, Z. (orgs.). A inovação democrática no Brasil: o orçamento participativo. São Paulo: Cortez, 2003.

Avritzer, L.; SouzA, C. H. L. (orgs.). Conferências nacionais: atores, dinâmicas e efetividade. Brasília: Ipea, 2013.

BAIOCCHI, G. "Activism and politics. The Porto Alegre experiment and deliberative democratic theory". Politics Society, vol. 29, n 43, 2001.

Militants and citizens: the politics of participatory democracy in Porto Alegre. Stanford: Stanford University Press, 2005.

BoschI, R. "Descentralização, clientelismo e capital social na governança urbana: comparando Belo Horizonte e Salvador". Dados, Rio de Janeiro, vol. 42, n 4, 1999.

BRASIL. Presidência da República. Secretaria Especial de Aquicultura e Pesca - Seap/PR. Caderno de resoluções da $1^{a}$ Conferência Nacional de Aquicultura e Pesca. Brasília: Seap/PR, $2003 a$.

Secretaria Especial de Aquicultura e Pesca - Seap/PR. Programação da $1^{a}$ Conferência Nacional de Aquicultura e Pesca. Brasília: Seap/PR, 2003b.

Secretaria Especial de Aquicultura e Pesca - Seap/PR. Portaria Seap, no 179, de 28 de agosto de 2003. Aprova o regimento da Conferência Nacional de Aquicultura e pesca e dá outras providências. Brasília: Seap/PR, 2003c.

- Ministério das Cidades - MCidades. Resoluções da $1^{a}$ Conferência Nacional das Cidades. Brasil: Mcidades, 2003d.

Ministério das Cidades - MCidades. Regimento Interno da $1^{a}$ Conferência Nacional das Cidades. Brasil: MCidades, 2003e.

Ministério do Meio Ambiente - MMA. Portaria no 359, de 09 de setembro de 2003. Aprova o regulamento geral da Conferência Nacional do Meio Ambiente e as normas básicas de sua primeira reunião. Brasil: MMA, $2003 f$. 
Brasil. Ministério do Meio Ambiente - MMA. Propostas da $1^{a}$ Conferência Nacional de Meio Ambiente. Brasília: ministério do meio ambiente. Brasil: MMA, 2003g.

. Ministério do Esporte - ME. Portaria no 13 de 03 de fevereiro de 2004. Aprova o regulamento geral da Conferência Nacional do Esporte e as normas básicas de sua primeira reunião. Brasil: ME, 2004a.

. Ministério do Esporte - ME. Conferência Nacional do Esporte. Esporte, lazer e desenvolvimento humano: documento final. Brasília: ME, $2004 \mathrm{~b}$.

. Secretaria Especial de Políticas para Mulheres - SPM/PR. Anais da $1^{a}$ Conferência Nacional de Políticas para Mulheres. Brasil: SPM, 2004c.

Secretaria Especial de Políticas de Promoção da Igualdade Racial - Seppir/PR. Relatório final da I Conferência Nacional de Políticas de Promoção da Igualdade Racial. Estado e sociedade promovendo igualdade racial. Brasil: Seppir, 2005.

Conferências Nacionais [online]. Secretaria de Governo, 2016. Disponível em <http://www.secretariadegoverno.gov.br/participacao-social/conferencias>. Acesso: 20 dez. 2016.

BUENO, L. "Políticas públicas do esporte no Brasil: razões para o predomínio do alto rendimento". Tese de Doutorado em Administração Pública e Governo. Fundação Getúlio Vargas, São Paulo, 2008.

CASTRo, L. A. B., et al. Situação atual da cadeia produtiva do pescado no litoral do estado de São Paulo. Governo do estado de São Paulo, Secretaria de Agricultura e Abastecimento, Agência Paulista de Tecnologia dos Agronegócios - Instituto de Pesca, Sér. Relat. Téc. São Paulo, n 21, 2005.

Coelho, V. S. P. Conselhos de políticas enquanto instituições políticas: o que está faltando?. In: Coelho, V. S. P.; Nobre, M. (orgs.). Participação e deliberação. Teoria democrática e experiências institucionais no Brasil contemporâneo. São Paulo: Editora 34, 2004.

. "A democratização dos Conselhos de Saúde: o paradoxo de atrair não aliados". Novos Estudos Cebrap, São Paulo, nº 78, 2007.

Cohen, J.; Fung, A. "Radical democracy". Swiss Journal of Political Science, vol. 10, n 4, p. 26-46, 2004.

Costa, A. A. A. "O movimento feminista no Brasil: dinâmicas de uma intervenção política". Niterói, vol. 5, n०2, p. 9-35, 2005.

CunhA, E. S. M. Conferências de políticas públicas e inclusão participativa. In: Avritzer, L.; SouzA, C. H. L. (orgs.). Conferências nacionais: atores, dinâmicas e efetividade. Brasília: Ipea, 2013.

FARIA, C. F. Do conflito jurídico ao consenso: uma versão da implementação do OP-RS. In: AVRITZER, L.; NAvarro, Z. (orgs.). A inovação democrática no Brasil: o orçamento participativo. São Paulo: Cortez, 2003.

FARIA, C. F.; LINS, I. L. Participação e deliberação nas Conferências de Saúde: do local ao nacional. In: AVRITZER, L; SouzA, C. H. L. (orgs.). Conferências nacionais: atores, dinâmicas participativas e efetividades. Brasília: Ipea, vol. 1, p. 73-94, 2013.

FARIA, C. F.; RibeIRo, U. C. Entre o legal e o real: o que dizem as variáveis institucionais sobre os conselhos municipais de políticas públicas? In: AVRITZER, L. (org.). A dinâmica da participação no Brasil. São Paulo: Cortez, 2010.

FARIA, C. F.; SiLVA, V. P.; LINS, I. L. "Conferências de políticas públicas: um sistema integrado de participação e deliberação?". Revista Brasileira de Ciência Política, Brasília, n 7, 2012. 
FISHER, F. Policy discourse and the politics of Washington think tanks. In: FISHER, F.; FORESTER, J. (eds.). The argumentative turn in policy analysis and planning. North Carolina: Duke University Press, 1993.

FUNG, A. Receitas para esferas públicas: oito desenhos institucionais e suas consequências. In: Coelho, V. S. P.; Nobre, M. (orgs.). Participação e deliberação. Teoria democrática e experiências institucionais no Brasil contemporâneo. São Paulo: Editora 34, 2004.

FUnG, A.; WRIGHT, E. O. Deepening democracy: institutional innovations in empowered participatory governance. London: Verso, 2003.

Goodin, R. E. "Sequencing deliberative moments". Acta Politica, vol. 40, n 2, p. 182-196, 2005.

HAJER, M. A., WAgenaAR, H. (eds.). Deliberative policy analysis: understanding governance in the network society. New York: Cambridge University Press, 1995.

HENDRIKS, C. M. "When the forum meets interest politics: strategic uses of public deliberation". Politics and Society, vol. 34, n 4, 2006.

JACOBI, P. Movimento ambientalista no Brasil. Representação social e complexidade da articulação de práticas coletivas. In: Ribeiro, W. (org.). Patrimônio ambiental. São Paulo: Edusp, p. 519-543, 2003.

MANSBRIDGE, J. Everyday talk in the deliberative system. In: MACEDo, S. (ed.). Deliberative politics: essays on democracy and disagreement. New York: Oxford University Press, 1999.

. Deliberative democracy or democratic deliberation? In: RoSENBERG, S. W. (ed.). Deliberation, participation and democracy: can the people govern? New York: Palgrave Macmillan, 2007.

"The place of self-interest and the role of power in deliberative democracy". The Journal of Political Philosophy, vol. 18, n 1, p. 64-100, 2010.

MARICATO, E. Reforma urbana: limites e possibilidades. Uma trajetória incompleta. In: RIBEIRO, L. C. Q.; SANTOS JR., O. A. (orgs.). Globalização, fragmentação e reforma urbana. Rio de Janeiro: Civilização Brasileira, p. 309-325, 1997.

. "Urbanismo na periferia do mundo globalizado: metrópoles brasileiras". São Paulo em Perspectiva, vol. 14, n 4, 2000.

PAPAdOPOUlOS, Y.; WARIN, P. "Are innovative, participatory, and deliberative procedures in policy making democratic and effective?". European Journal of Political Research, vol. 46, n 4, p. 445472, 2007.

Petinelli, V. "As conferências públicas nacionais e a formação da agenda de políticas públicas do governo federal (2003-2010)". Opinião Pública, Campinas, vol. 17, n 1, p. 228-250, 2011.

Contexto político, natureza da política, organização da sociedade civil e desenho institucional: alguns condicionantes da efetividade das conferências nacionais. In: AVRITZER, L.; SouzA, C. H. L. (orgs.). Conferências nacionais: atores, dinâmicas e efetividade. Brasília: Ipea, 2013.

"Uma análise dos condicionantes da capacidade de influência das conferências de políticas públicas sobre os programas das respectivas políticas setoriais: o caso da $1^{\mathrm{a}} \mathrm{CAP}, 1^{\mathrm{a}}$ ConCidades, $1^{\text {a }}$ CMA, $1^{\text {a }}$ CE, $1^{\text {a }}$ CPM e $1^{\text {a }}$ CPIR". Tese de Doutorado em Ciência Política. Universidade Federal de Minas Gerais, Belo Horizonte, 2014. 
Petinelli, V. "Aferindo a capacidade de influência das conferências de políticas públicas sobre os programas de políticas". Opinião Pública, vol. 21, n 3, p. 643-672, 2015.

PogREBINSCHI, T. Conferências nacionais e políticas públicas para grupos minoritários. In: AVRITZER, L.; SouzA, C. H. L. (orgs.). Conferências nacionais: atores, dinâmicas e efetividade. Brasília: Ipea, 2013.

POGREBINSCHI, T.; SANTOS, F. "Participação como representação: o impacto das conferências nacionais de políticas públicas no Congresso Nacional". Dados, vol. 54, n 3, 2011.

RAmos, A. Conferência nacional de política para as mulheres: interações discursivas e implicações para a legitimidade epistêmica. In: AVRITZER, L.; SouzA, C. H. L. (orgs.). Conferências nacionais: atores, dinâmicas e efetividade. Brasília: Ipea, 2013.

RAMOS, A.; FARIA, C. F. "Las conferencias de políticas públicas en Brasil: hacia un sistema integrado de participación y deliberación a nivel nacional". Revista Española de Ciencia Política, n 32, p. 4363, 2013.

Ribeiro, M. "As políticas de igualdade racial no Brasil". Revista Análises e Propostas, n 35, 2009.

SCHEVISBISKI, R. S. "Regras institucionais e processo decisório de políticas públicas: uma análise sobre o Conselho Nacional de Saúde (1990-2006)". Dissertação de Mestrado em Ciência Política. Universidade de São Paulo, São Paulo, 2007.

Silva-SÁnCHEZ, S. S. "Política de meio ambiente no Brasil: a construção da cidadania ambiental". Revista Plural de Sociologia, vol. 6, p. 20-46, 1999.

SouzA, C. H. L. A que vieram as conferências nacionais? Uma análise dos objetivos dos processos realizados entre 2003 e 2010. Brasil: Ipea, 2013.

TATAGiBA, L.; TeiXEIRA, A. C. "Dinâmicas participativas institucionalizadas e produção de políticas públicas". In: Anais do $6^{\circ}$ Encontro da $A B C P$, Campinas, 2008.

Vieira, L.; CADeR, R. "A política ambiental do Brasil ontem e hoje". Revista Eco 21, no 129, ago. 2007.

VITALE, D. Democracia direta e poder local: a experiência brasileira do orçamento participativo. In: Coelho, V. S. P.; Nobre, M. (orgs.). Participação e deliberação. Teoria democrática e experiências institucionais no Brasil contemporâneo. São Paulo: Editora 34, 2004. 


\section{Resumo}

A quem servem as conferências de políticas públicas? Desenho institucional e atores beneficiados

Este artigo examina a relação entre o desenho institucional de conferências de políticas públicas e os atores beneficiados pelas propostas nelas aprovadas. Avalia-se se e em que medida as propostas finais da $1^{\text {a }}$ Conferência de Aquicultura e Pesca, de Cidades, de Meio Ambiente, de Esportes, de Políticas para Mulheres e de Políticas de Promoção da Igualdade Racial, as quais interessavam diretamente a alguma(s) categoria(s) específica(s) do segmento estatal e não estatal presente(s) nestas, refletiram o grau de inclusão política da conferência, entendido aqui não só enquanto inclusão de vozes, mas também enquanto tradução do direito à voz em decisão. Para tanto, cada proposta aprovada foi classificada segundo $\mathrm{a}(\mathrm{s})$ categoria(s) às quais interessava diretamente. A análise permitiu constatar que diferentes desenhos produzem resultados distintos, sendo a combinação entre dinâmica representativa e deliberativa decisiva na capacidade de influência dos atores nas propostas finais aprovadas.

Palavras-chave: conferências; inclusão política; desenho; atores; propostas

\section{Abstract \\ Who do public policy conferences serve? Institucional design and stakeholders}

This article examines the relationship between the institutional design of conferences on public policies and the actors benefiting from the proposals approved therein. The final recommendations of the $1^{\text {st }}$ Conference on Aquaculture and Fisheries, on Urban Policy, on Environment, on Sports and the $1^{\text {st }}$ Conference on Policies for Women and Policies for the Promotion of Racial Equality, which benefited a/some specific segment(s) participating in it, reflected the degree of political inclusion of the conference, understood not only as an inclusion of voices, but also as a translation of the right to a voice in decision-making. To do so, each approved proposal was classified according to the segment(s) directly interested. The analysis showed that different designs produce different results. Representation and deliberative rules play a key role in determining who most influences the proposals approved in those arenas.

Keywords: conferences; political inclusion; design; stakeholders; proposals

\section{Resumen}

¿A quién sirven las conferencias de políticas públicas? Diseño institucional y actores beneficiados

Este artículo analiza la relación entre el diseño institucional de conferencias sobre políticas públicas y los actores que se benefician de las propuestas aprobadas. Se evaluó si y en qué medida las recomendaciones finales de la $1^{\text {a }}$ Conferencia de Acuicultura y Pesca, de las ciudades, de Medio Ambiente, de Deportes y la $1^{a}$ Conferencia de Política para la Mujer y de Promoción de Igualdad Racial, que directamente ha interesado a algún(os) segmento(s) específico(s) presente(s) en la misma, ha reflejado el grado de inclusión política de la conferencia, entendida aquí no sólo como la inclusión de voces, sino también como la traducción del derecho a voz en decisión. Por lo tanto, cada propuesta aprobada fue clasificada de acuerdo al(Ios) segmento(s) directamente interesados. El análisis permitió establecer que diferentes diseños producen diferentes resultados, y la dinámica de representación y de deliberación influencian decisivamente en la capacidad de los segmentos en aprobar las propuestas en la conferencia.

Palabras clave: conferencias; inclusión política; diseño; actores; propuestas 


\section{Résumé}

À qui servent les conférences sur les politiques publiques? Design institutionnel et les acteurs bénéficiaires

Cet article examine la relation entre la conception institutionnelle des conférences sur les politiques publiques et les acteurs à qui bénéficient les propositions qui y sont approuvées. Il est évalué si et dans quelle mesure les recommandations finales de la $1^{\mathrm{e}}$ Conférence d'Aquaculture et de Pêche, Urbaine, de I'Environnement, des Sports et la 1ère Conférence de la politique pour les femmes et de la promotion des politiques d'égalité raciale, qui intéressaient directement certains(s) segment(s) spécifique(s) présent(s) à cette conférence; ils reflètent le degré d'inclusion politique de la conférence, entendue ici non seulement comme l'inclusion des voix, mais aussi comme une traduction du droit à une voix dans la décision. Par conséquent, chaque proposition approuvée a été classée selon le(s) segment(s) qui s'y intéressent directement. L'analyse a permis d'établir que des conceptions différentes produisent des résultats différents, et la dynamique représentative et délibérative influence de façon décisive la capacité des segments d'approuver les propositions dans la conférence.

Mots-clés: conférences; inclusion politique; conception institutionnelle; acteurs; propositions

Artigo submetido à publicação em 13 de janeiro de 2017. Versão final aprovada em 10 de julho de 2017. 